\title{
Effect of trapped air on wave forces on coastal bridge superstructures
}

\author{
Mohsen Azadbakht ${ }^{1}$. Solomon C. Yim ${ }^{1}$
}

Received: 18 April 2015 / Accepted: 2 January 2016 / Published online: 16 February 2016

(C) Springer International Publishing Switzerland 2016

\begin{abstract}
Recent hurricanes have caused significant damage to coastal bridges of southern US coastal areas along the Gulf of Mexico. Previous studies have identified trapped air between bridge girders as a significant factor in increasing wave uplift loads on coastal bridge superstructures. The objective of this study is to investigate and quantify this effect. A numerical parametric study is conducted to examine the influence of this trapped air effect on resultant wave forces under different wave conditions for a variety of bridge geometry. Numerical results show that the wave loads on a bridge deck superstructure are sensitive to the amount of trapped air between the bridge girders. The wave uplift force is found to be $57-88 \%$, on average, lower for a wide range of wave periods when the effect of the trapped air is neglected. In addition, the effectiveness of the presence of air vents in reducing the air pressure between girders and the wave forces is evaluated. Numerical results indicate that the vertical (uplift) wave forces acting on the bridge superstructures can be reduced by about $56 \%$ on average using deck air vents. Numerical results of the computational analyses of the wave forces on coastal bridge superstructures are also compared to estimations of the wave force computed from design expressions in AASHTO. It is found that while AASHTO estimations of the horizontal wave force are reasonable, estimations of the vertical forces are less consistent and can vary from overly conservative for larger waves to underpredicting for smaller waves.
\end{abstract}

Solomon C. Yim

Solomon.Yim@oregonstate.edu

Mohsen Azadbakht

azadbakm@onid.orst.edu

1 School of Civil and Construction Engineering, Oregon State University, Corvallis, OR, USA
Keywords Bridge superstructures - Wave - Forces · Height $\cdot$ Period $\cdot$ Trapped air effect $\cdot$ Uplift force

\section{Introduction}

Recent hurricanes have caused significant damage to coastal bridges in the southern US coastal areas along the Gulf of Mexico (Padgett et al. 2008). Figure 1 shows the extent of the damage to US 90 Biloxi Bay Bridge after Hurricane Katrina in 2005. After the hurricane, extensive research studies were conducted in recent years to examine wave forces on coastal bridges both experimentally and numerically (e.g., Douglass et al. 2006; Bradner 2008; Bradner et al. 2011; Robertson et al. 2007a,b, 2011; Jin and Meng 2011). A review of previous studies of wave forces on coastal highway bridges indicated the importance of the trapped air between the bridge girders on the resultant wave force on bridges (Sheppard and Marin 2009b; Bozorgnia et al. 2010; Cuomo et al. 2009). While there is a body of literature on wave forces on bridge superstructures, few studies to date have focused on the evaluation of the effect of trapped air.

A literature review of studies investigating different aspects of the wave loading on coastal bridges is presented in this section. Failure modes of the coastal bridges under wave loading and numerical and experimental investigations on wave loads on bridge superstructures as well as current methods of predicting the wave loads on coastal bridges are also examined.

Robertson et al. $(2007 \mathrm{a}, \mathrm{b})$ reported inundation due to storm surge and wind-induced wave actions as the primary cause of damage to coastal infrastructure. The space bounded between girders and diaphragms was defined as the potential trapped air volume as the water level reaches the bottom of the bridge girders. Okeil and Cai (2008) recommended using 


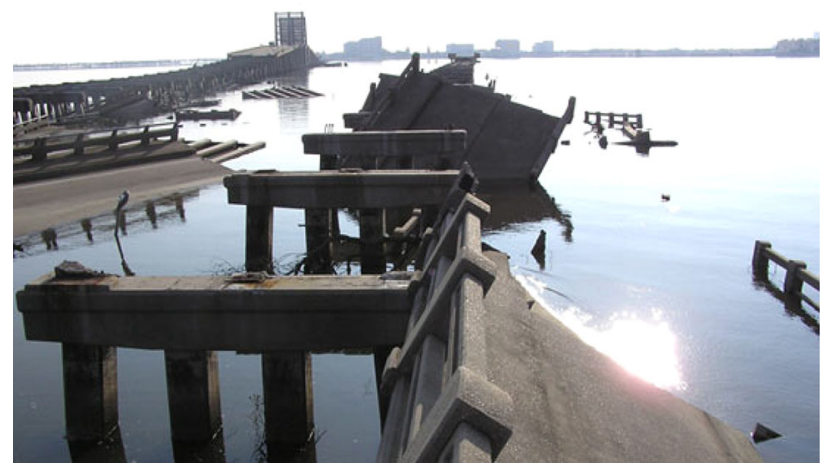

Fig. 1 Failure of the US 90 Biloxi Bay Bridge during the Hurricane Katrina (photo by Yim)

partially grated deck as a possible countermeasure to reduce loads on deck, because it would permit the trapped air to escape. Cuomo et al. (2009) performed a set of experimental studies to measure wave loading on the bridge superstructures. They found that the quasi-static upward loads on bridge deck were lower when decks had air vents. These air vents were believed to be effective in reducing the load on the bridge deck. These air vents led to higher quasi-static downward loads on the bridge decks. Cuomo et al. (2009) also reported that the compressed air pocket trapped between girders and diaphragms could decrease the wave impact pressure, as part of the wave energy was dissipated in compressing the air.

Douglass et al. (2006) provided a set of equations to estimate horizontal and vertical wave loads on bridge decks where each load component consists of two parts, a slowly varying load and an impact load. Sheppard and Marin (2009a) reported the drag, inertia, buoyancy, and slamming forces as forces acting on a structure due to the presence of an accelerating fluid with a free surface. Sheppard and Marin (2009b) reported that the air trapped between girders acted as the spring in a spring-mass system. These air pockets reduced the magnitude of slamming force and increased the duration of the wave force. In the experimental study, they obtained slamming forces by subtracting the quasi-static (low frequency) forces from the measured forces. Sheppard and Marin (2009b) reported that the presence of the trapped air increased both the buoyancy and the inertia forces with increasing effective volume of the structure. It was also observed that the steeper waves and larger-spaced girders led to less trapped air. The magnitude of the vertical slamming force was observed to be reduced for the model with smaller number of girders. Air pockets were deemed to act as an extension of the structure surface and also act like a spring resulting in lower magnitude and longer duration of force. The oscillations in the slamming force were reported to be equal to the number of air chambers (number of girders minus one) provided that the wave has enough energy to generate the multiple slamming forces before being totally dissipated (Sheppard and Marin 2009b).

Huang and Xiao (2009) investigated wave loading on the Escambia Bay Bridge during Hurricane Ivan using a numerical model based on the Reynolds averaged NavierStokes equations (RANS) with a k- $\varepsilon$ closure model. They found that the maximum horizontal and uplift forces did not occur at the same time. It was also shown that for cases where the maximum uplift force was less than the weight of the bridge deck, the maximum horizontal force was large enough to move the simply supported bridge deck laterally. Bozorgnia et al. (2010) utilized a commercial CFD code, STAR CCM+, to simulate wave loads on coastal bridges. Using a 2D numerical model of the I-10 Bridge across the Mobil Bay, they found the wave load time history to be a combination of impulsive and quasi-static forces. They modeled the air vents as slits in the bridge deck and rails and reported a significant reduction in uplift forces due to the presence of the air vents. They also reported that when air vents were present, the time histories of vertical wave loads showed fewer oscillations. However, it did not influence the overall behavior of the horizontal wave forces.

Bozorgnia and Lee (2012) performed a set of 2D and 3D CFD simulations and provided a comparison with experimental measurements of Bradner (2008) on wave forces on bridge superstructures. Using a commercial software, STAR $\mathrm{CCM}+$, they found that the magnitude of the resulting wave forces was sensitive to mesh size and computational time step. They reported that wave force time histories were more oscillatory when smaller time steps were used for simulations, because simulations with large time steps were not able to capture the oscillations in wave forces. They also concluded that 2D simulations were not able to capture the air movement in the transverse direction, resulting in nonoscillatory wave force time histories, whereas $3 \mathrm{D}$ simulations showed the presence of these oscillations in wave forces.

Recent studies conducted at the University of Hawaii at Manoa have focused on experimental and numerical investigations of cnoidal and solitary wave forces on flat plates and coastal bridges (Hayatdavoodi and Ertekin 2015a,b; Hayatdavoodi et al. 2014, 2015; Seiffert et al. 2014a, b, 2015). Hayatdavoodi et al. (2014) conducted both experimental and numerical studies to investigate wave forces on coastal bridges. The effects of several parameters such as water depth, wave amplitude, and submergence depth were studied. Additionally, it was shown that the developed computational model could accurately predict the wave forces on bridges. Hayatdavoodi et al. (2014) also showed that the entrapped air could significantly increase the uplift forces on bridges. Seiffert et al. (2014a), through experimental investigation of wave forces on a scaled bridge, observed increase in wave uplift forces when the effect of trapped air was included. 
They also reported that entrapped air under the bridge could lead to smaller horizontal wave forces.

The objective of this study is to investigate and quantify the effect of the trapped air between bridge girders on the wave loads on bridge superstructures. A parametric study is conducted to investigate the influence of the trapped air on resultant wave forces under various wave field conditions (e.g., different wave heights and wave periods) and bridge geometry characteristics (e.g., number of bridge girders). The effectiveness of the presence of air vents in reducing the air pressure between girders and the wave forces is evaluated. A comparison between numerical results of the current study and AASHTO (2008) recommendations is also provided.

\section{Numerical modeling and model validation}

\subsection{Experimental setup and measurements of Bradner et al.}

Bradner et al. (2011) performed an experimental study on a 1:5 scale model of the I-10 Bridge over the Escambia Bay, Florida, damaged by Hurricane Katrina. A photo of the experimental setup is provided in Fig. 2. The length (normal to wave propagation direction), width (parallel to wave propagation direction) and height of the bridge model were $3.45,1.94$, and $0.28 \mathrm{~m}$, respectively. The water depth ranged from 1.61 to $2.17 \mathrm{~m}$. Rigid and flexible spring connections were used between the bridge superstructure and substructure. It should be noted that connection flexibility was only provided in the horizontal direction. The spring stiffness was chosen to match the fundamental frequency of the actual bridge. Different combinations of wave height, wave period, still water level (SWL), and bridge clearance (i.e., the distance between the bottom of the bridge girder and the SWL) were studied. The (very high-frequency) response of the reac-

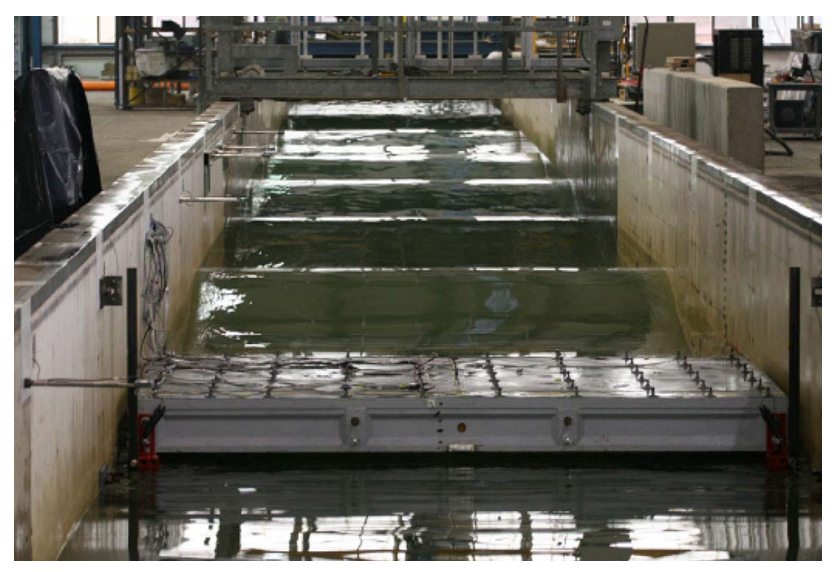

Fig. 2 Experimental setup to measure wave forces on a coastal bridge (Bradner 2008) tion frame supporting the bridge specimen was eliminated from the wave loading records by setting a low-pass filter determined according to the natural frequency of the reaction frame system measured in an impact test. Bradner et al. (2011) concluded that the wave height had the most significant effect on the resulting wave loads. Larger wave heights led to larger wave forces. The second most important factor was the elevation of the SWL. It was observed that a higher SWL led to larger wave forces until it reached the bottom of the bridge girders. A further rise in the SWL resulted in a decrease or no change in the measured forces. Vertical forces measured in the rigid and flexible setups were found to be similar. However, the horizontal forces between the two setups were quite different. The horizontal force in the flexibly supported bridge deck is smooth and oscillatory, with significant negative value as a result of the dynamic response of the structure. The maximum horizontal and vertical forces for rigid setup were found to occur at approximately the same time, but for the flexible setup there was a time shift between the maxima of the horizontal and vertical forces.

\section{Numerical model description}

A finite-element analysis (FEA) code, LS-DYNA, is used to perform the CFD analysis and compute the wave loading on coastal bridges. The numerical code solves the Navier-Stokes (NS) equations to obtain the pressure field and consequently forces on the structure. An arbitrary Lagrangian-Eulerian (ALE) formulation with a modified adaptive, unstructured grid was used to track the fluid particles on the fluid free surface (Hallquist 2006).

\subsection{Governing equations}

In the ALE description, an arbitrary referential coordinate is introduced in addition to the Lagrangian and ALE coordinates (Souli and Benson 2010). The material time derivative of an arbitrary function $g$ with respect to the reference coordinate can be described as:

$\frac{\mathrm{d} g(\vec{X}, t)}{\mathrm{d} t}=\frac{\partial g(\vec{x}, t)}{\partial t}+(\vec{v}-\vec{w}) \cdot \overrightarrow{\operatorname{grad}} g(\vec{x}, t)$

where $\vec{X}$ is the Lagrangian coordinate, $\vec{x}$ the ALE coordinate, $\vec{v}$ the particle velocity, and $\vec{w}$ the grid velocity of the numerical simulation. The ALE differential form of the conservation equations for mass, momentum, and energy are:

Mass: $\quad \frac{\partial \rho}{\partial t}+\rho \operatorname{div}(\vec{v})+(\vec{v}-\vec{w}) \cdot \overrightarrow{\operatorname{grad}}(\rho)=0$,
Momentum: $\quad \rho \frac{\partial \vec{v}}{\partial t}+\rho(\vec{v}-\vec{w}) \cdot \overline{\overline{\operatorname{grad}}}(\vec{v})=\overrightarrow{\operatorname{div}}(\overline{\bar{\sigma}})+\vec{f}$, 
Fig. 3 FE Model developed to simulate the wave impact on the bridge superstructure. a Bridge model with positive directions of horizontal and uplift wave forces shown. b FE domain including water and air and bridge superstructure

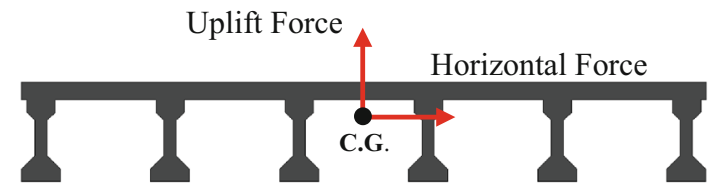

(a)

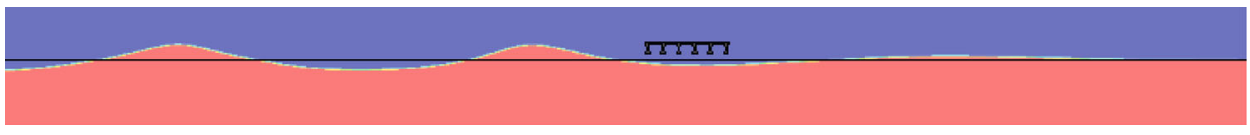

(b)

Energy: $\quad \rho \frac{\partial e}{\partial t}+\rho(\vec{v}-\vec{w}) \cdot \overrightarrow{\operatorname{grad}}(e)=\overline{\bar{\sigma}}: \overline{\overline{\operatorname{grad}}}(\vec{v})+\vec{f} \cdot \vec{v}$,

where $\rho$ is the mass density, $\vec{f}$ the body force vector, and $e$ the total energy. $\overline{\bar{\sigma}}$ denotes the total Cauchy stress tensor given by:

$\overline{\bar{\sigma}}=-p \overline{\bar{I}}+\mu\left(\overline{\overline{\operatorname{grad}(\vec{v})}}+\overline{\overline{\operatorname{grad}(\vec{v})}}^{T}\right)$,

where $p$ is the pressure, $\overline{\bar{I}}$ the identity tensor, $\mu$ the dynamic viscosity, and $(\vec{v}-\vec{w})$ the convective velocity across the grid. Note that the symbols $\overrightarrow{()}, \overline{\overline{(~)}}$ stand for a vector and a secondorder tensor, respectively, grad stands for the gradient of (), () ${ }^{T}$ stands for transpose of the quantity inside the parenthesis, and: stands for the scalar contraction of two second-order tensors.

An equation of state with a linear polynomial form is used to define the initial thermodynamic state of the material, with the pressure given by:

$p=C_{0}+C_{1} \zeta+C_{2} \zeta^{2}+C_{3} \zeta^{3}+\left(C_{4}+C_{5} \zeta+C_{6} \zeta^{2}\right) E$,

where $C_{0-6}$ are user-defined constants, $E$ is initial energy per initial volume, and the volumetric parameter $\zeta$ is defined as:

$\zeta=\frac{1}{V}-1$,

where $V$ is relative volume given as:

$V=\frac{\rho_{0}}{\rho}$

with $\rho_{0}$ as the reference mass density (which might be different than the current mass density if the material experiences compression or expansion throughout the simulation). The constant $C_{1}$ in Eq. 6, when used by itself, is the elastic bulk modulus. Providing this constant only and setting all other constants to zero are sufficient to define the equation of state if the pressure is not significantly influenced by temperature changes.

\subsection{Numerical model validation}

A two-dimensional (2D) FE model is developed in LSDYNA to perform the CFD simulations. The FE model of the experimental setup in Bradner (2008) is presented in Fig. 3 where the bridge clearance is half of its height (distance between bottom of bridge girder and top of deck). The fixed bridge superstructure is modeled as a rigid body. Stokes fifth-order wave theory (Fenton 1985) is used to generate the wave at the inflow (left) boundary condition for all the simulations. Simple sinusoidal waves are employed here to keep the excitation simple and allow us to focus on the physics of impact and the effect of air trap.

To study the effect of air trapped between bridge girders, two different approaches are used to model the air in the FE domain. The first model contains the "real" air with associated density and equation of state, while in the second model a single-phase simulation is conducted. The air domain is modeled as a void part for the second approach. This void part simply defines a meshed domain for the adjacent fluid material to flow into as needed during the simulation. This approach represents a situation where the air trapped between the bridge girders has no effect on the wave forces on the bridge and imposes no resistance against waves striking the bottom of the bridge deck from below.

The experimental measurements of the wave force on the bridge superstructure with a rigid setup provided in Bradner (2008) are used to validate the results of numerical simulations including trapped air effect. The total horizontal and vertical wave loads acting on the bridge are computed and compared against experimental measurements in Fig. 4. The force measurements obtained from the experimental setups with two different SWLs are used here. In the first setup, the low chord (bottom of girders) elevation of the bridge model is higher than the SWL elevation. The bridge model clearance in this case is equal to half of the bridge model's 


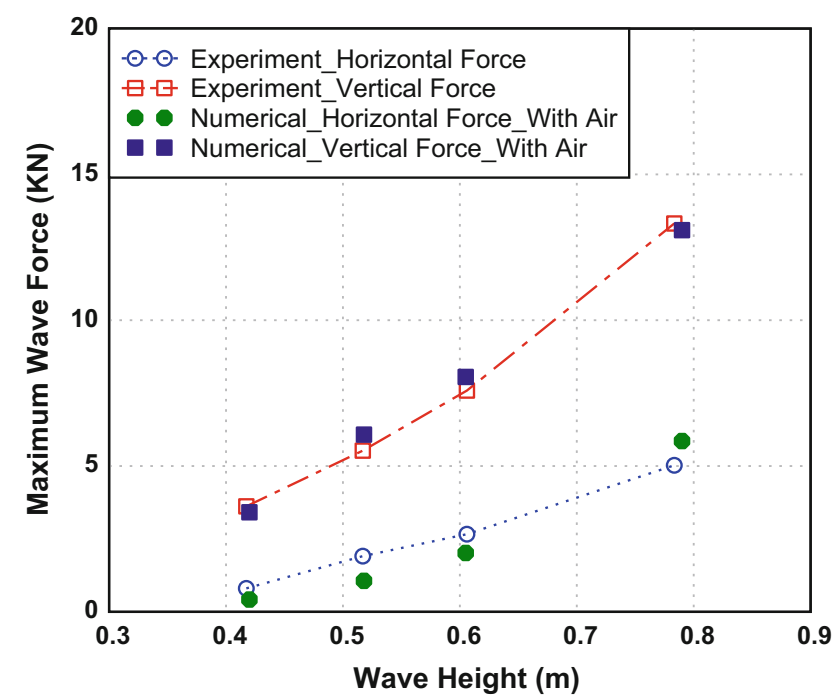

(a)

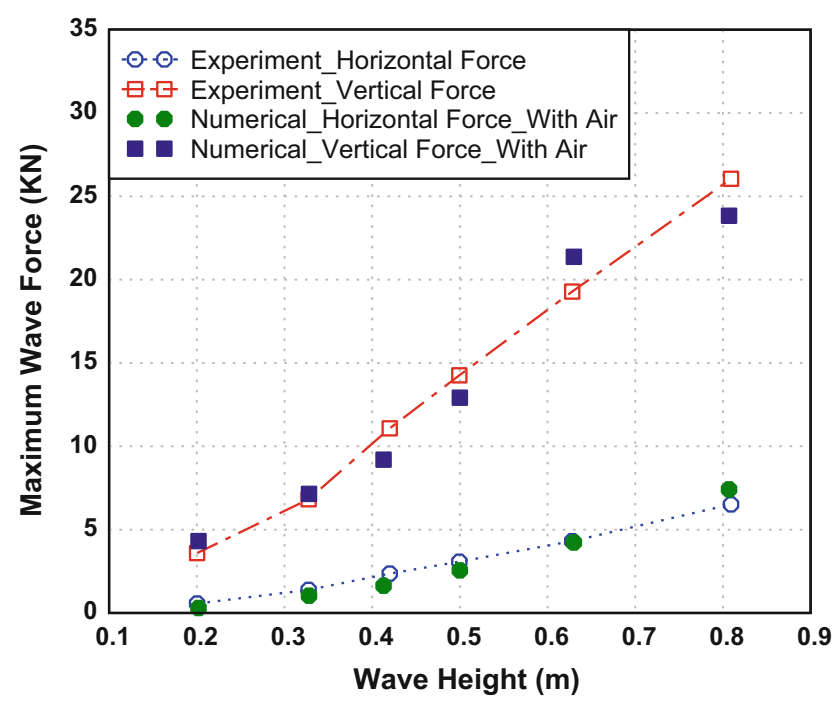

(c)

Fig. 4 Comparison of the experimental measurements and numerical computations of the horizontal and vertical wave loads on bridge model for different bridge clearances. a Bridge clearance: half of bridge

height. In the second setup, the bridge model is placed at the SWL elevation. Numerical simulations with these two bridge clearances are conducted for various wave heights, while the wave period is held constant at $2.5 \mathrm{~s}$. Water depth, bridge width, and deck thickness are 1.75, 1.94, and $0.05 \mathrm{~m}$, respectively. Several preliminary models with different mesh size and time step size were developed. The mesh size and the computational time step are $25 \mathrm{~mm}$ and $3 \mathrm{E}-5 \mathrm{~s}$, respectively. Figure 4 shows good agreement between numerical simulation results and the experimental measurements of both horizontal and vertical wave forces acting on the bridge model. The results demonstrate that the experimental behav-

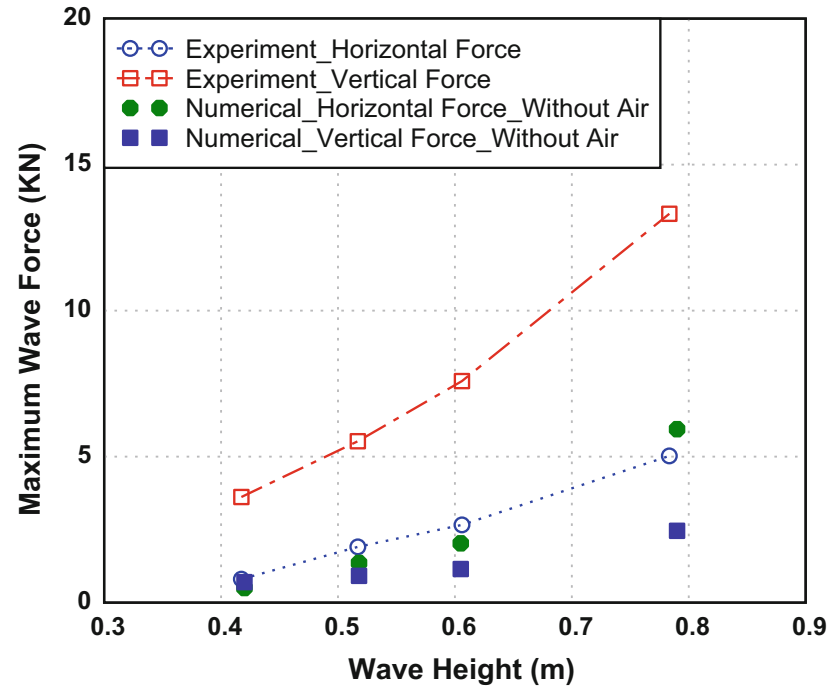

(b)

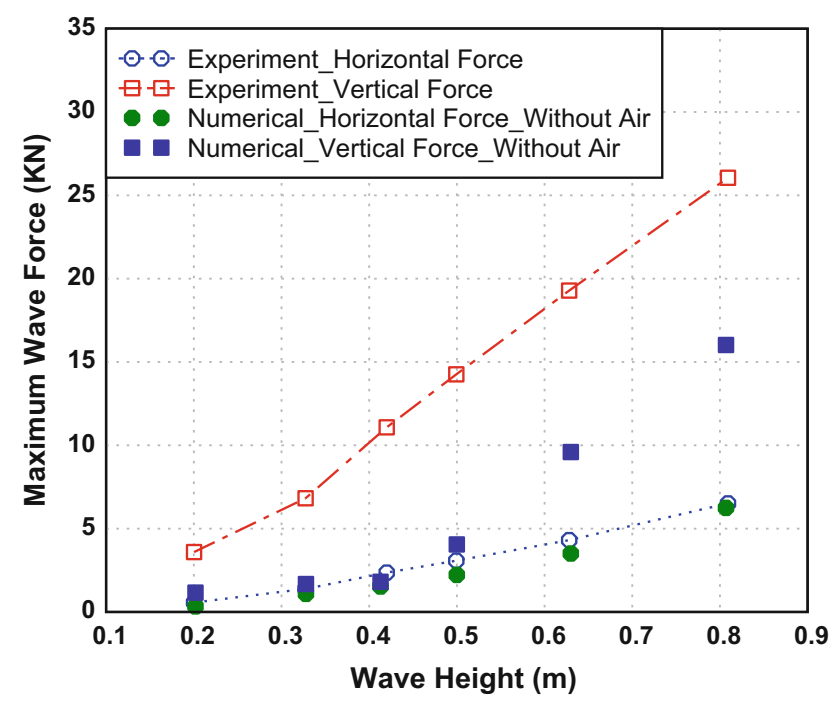

(d)

model's height, two-phase modeling. b Bridge clearance: half of bridge model's height, single-phase modeling. c Bridge clearance: 0.0, twophase modeling. d Bridge clearance: 0.0, single-phase modeling

ior can be considered two dimensional, and the 2D numerical model employed here is able to accurately predict the wave forces on the bridge superstructures. It should be noted that computational measurements of wave forces on the bridge are obtained by algebraic summation of fluid forces acting on the bridge superstructure boundary. In other words, in the numerical model, wherever there is an overlap between fluid domain (i.e., air and water) and structure domain (i.e., bridge), a contact surface is generated. Then, pressure on this contact surface is computed by adding static and dynamic components of pressure from adjacent fluid cell, resulting in calculation of force on each contact surface. Ultimately, 


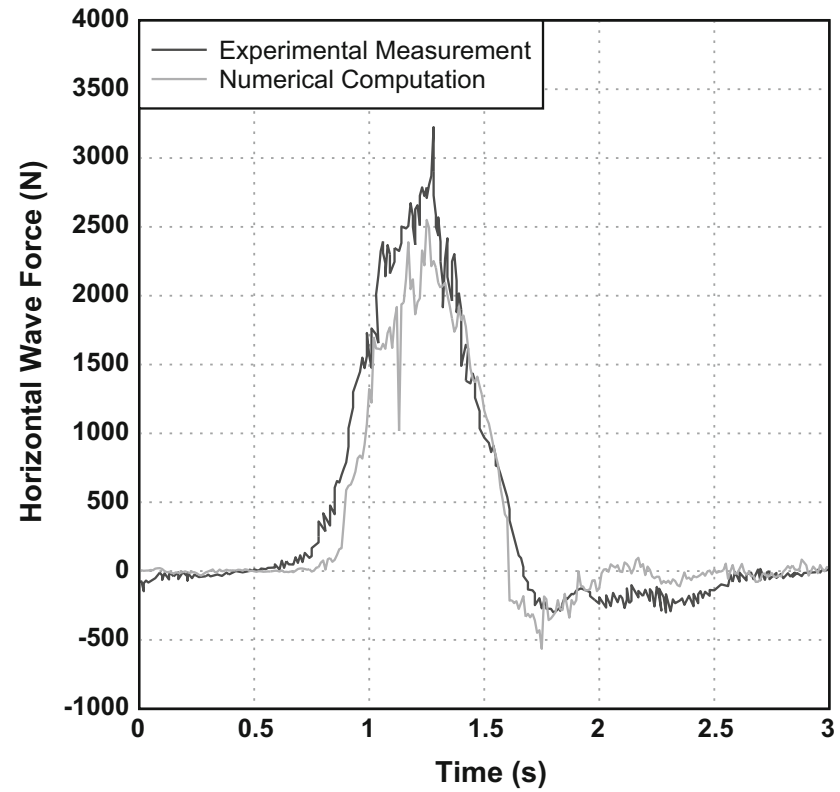

(a)

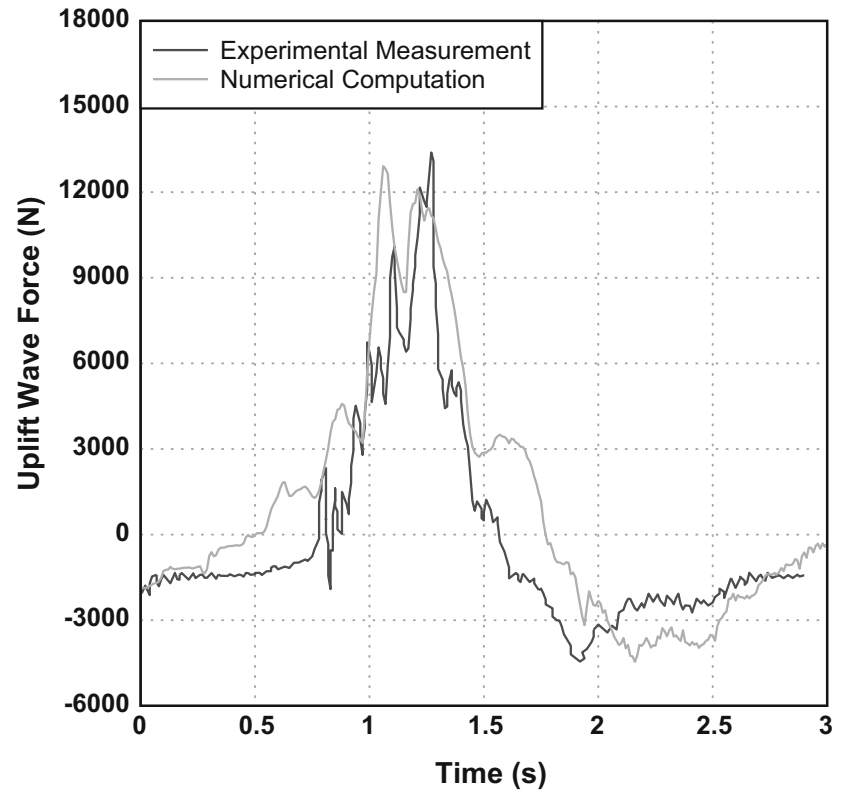

(b)

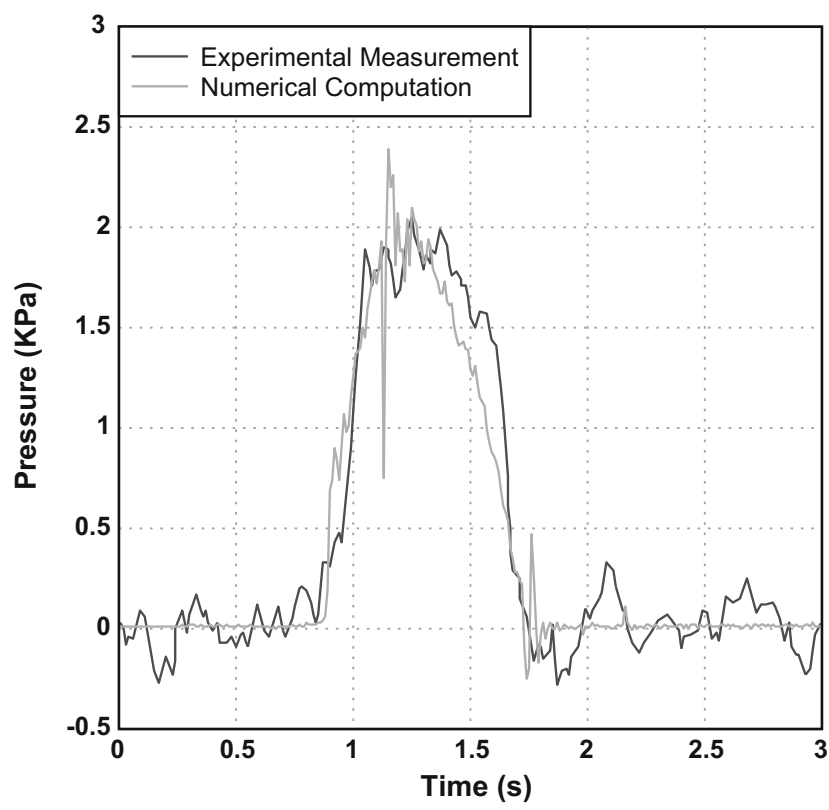

(c)

Fig. 5 Comparison between numerical predictions and experimental measurements of time histories of the total horizontal and uplift wave forces and pressure on the bridge specimen. a Total horizontal force.

integration of all these forces on the structure leads to determination of magnitude and direction of the resultant force.

Furthermore, to establish a more detailed validation of the numerical model, experimental measurements of wave force and pressure time history presented in Bradner (2008) are compared to the simulations using the present numerical model. Figure 5 depicts the time histories of the total horizontal and uplift wave forces and pressure time history at a b Total uplift force. c Pressure at the middle of the outer face of the offshore external girder

specific location on the bridge specimen. These time histories are from a case where the low chord (bottom of girders) of the bridge specimen was set at the SWL with corresponding water depth, wave height and wave period of $1.75 \mathrm{~m}, 0.5 \mathrm{~m}$, and $2.5 \mathrm{sec}$, respectively. The experimental measurement of the pressure time history in Fig. $5 \mathrm{c}$ corresponds to the center of the outer face of the offshore external girder. As observed from the figure, the numerical model computations of both 
Uplift Force

Fig. 6 FE model used to compute wave uplift force on a flat plate

the horizontal and uplift forces match well with experimental measurements. Both time histories of the experimental measurement and numerical computation of the uplift force illustrate five reasonably distinguishable oscillations. Note that the five oscillations correspond to the sequential compression of the trapped air in the five air chambers in a six-girder bridge. These results are in good agreement with the findings of Sheppard and Marin (2009b). Numerical computation of the pressure time history also shows very good agreement with the experimental results.

To validate the single-phase model, numerical results of two-phase and single-phase simulations are computed and compared for a case where the effect of trapped air is minimal. Figure 6 shows the model developed to compute the uplift wave force on a flat plate. The plate is $9.7 \mathrm{~m}$ wide and $2.54 \mathrm{~m}$ in height. The plate is placed $0.50 \mathrm{~m}$ above the SWL where the water depth is $8 \mathrm{~m}$. Simulation is conducted for a case where the wave height is $3 \mathrm{~m}$ and the wave period is $8 \mathrm{~s}$.

Since trapped air effect is minimal in this numerical "experimental" setup in comparison with bridge with girders, both two-phase and single-phase models should predict identical wave load on the plate. Figure 7a, b shows the uplift wave loads obtained for the two-phase flow and single-phase flow for the response to the second cycle of the incoming periodic wave train, respectively. Figure $7 \mathrm{c}$, d shows a direct comparison of computed force time histories and the same data filtered through a low-pass filter, respectively. The comparisons indicate that both FE models lead to practically the same result, validating the single-phase model with no trapped air effect (TAE). Note that the simulation ignoring the TAE shows more high-frequency peaks, whereas the one incorporating the air effect depicts a much smoother force time history, as the air serves as a damping mechanism.

After the single-phase model is validated, another set of numerical simulations is performed for scenarios in which the effect of the trapped air between bridge girders is neglected. As shown in Fig. 4, the vertical (uplift) wave force acting on the bridge model is significantly influenced by the presence of the trapped air between the bridge girders, as the simulation results of the vertical force for the cases neglecting the TAE clearly underestimate the vertical wave forces. It can also be observed from Fig. 4 that the increasing effect on vertical wave forces due to the trapped air is higher for smaller waves where the wave crest elevation is lower than the bridge deck elevation. Simulation results in Fig. 4 also show that the effect of the trapped air is more prominent for the cases with higher bridge clearance. This suggests that although the total wave vertical forces are smaller for higher bridge clearances, the TAE is more significant. This behavior is similar to the wavebridge interaction in the cases where bridge clearance is lower and the wave height is smaller, as explained earlier. It should be noted that, in reality, scenarios in which $0 \%$ (i.e., single phase) or $100 \%$ (i.e., two phase) of air under bridge deck is trapped are not likely to occur. It is expected that, even for a bridge with deep girders, some of the trapped air is vented out from the sides. Similarly, for a bridge equipped with air vents, some air entrapment is expected. Results of the singlephase and two-phase analyses provide the extreme ends of the air entrapment spectrum.

\section{Numerical parametric study}

Upon validating the single-phase and two-phase flow models, the effect of the trapped air on the dynamics of the fluid flow field is examined in the first part of this section. The second part presents the results of a parametric study to quantify the TAE on the uplift wave forces on bridge superstructures. The third part defines a parameter which quantifies the TAE on the uplift wave forces. Numerical simulations directly solve Eqs. (2) through (5) using an explicit arbitrary Lagrangian-Eulerian integration procedure (see Hallquist 2006). The fluid free surface is tracked by the convection of the Lagrangian coordinates of the fluid boundary nodes. The interior of the fluid domain is solved using the ALE technique, which solves the flow variable and convects the coordinates, but allowing flow to cross the element boundaries.

\subsection{Trapped air effect on the hydrodynamics}

The water flow field is highly influenced by the amount of trapped air between the bridge girders during the wave actions as the amount of the trapped air can significantly increase the uplift force acting on the bridge superstructure. This trapped air is also reported to be responsible for increasing the duration of the wave force action on the bridge superstructure (Sheppard and Marin 2009a, b). Figure 8 shows the hydrodynamic flow field of two numerical simulations when the water depth, wave height, wave period, bridge width, and deck thickness are $8,2 \mathrm{~m}, 8 \mathrm{~s}, 9.7$, and $0.25 \mathrm{~m}$, respectively. The results of a single-phase simulation where the effect of the trapped air between the bridge girders is neglected are shown on the left, while results of a two-phase simulation in which the trapped air is modeled properly are provided on the right. As shown in the figure, the trapped air between the bridge girders imposes a resistance against the wave impacting the bridge superstructure, and for this particular case preventing it from reaching the bottom of the deck and significantly modifying the wave profile under 


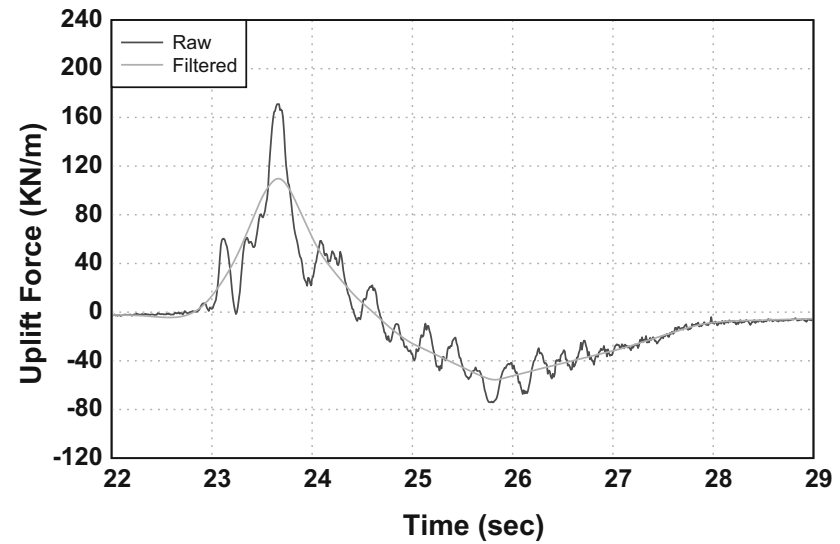

(a)

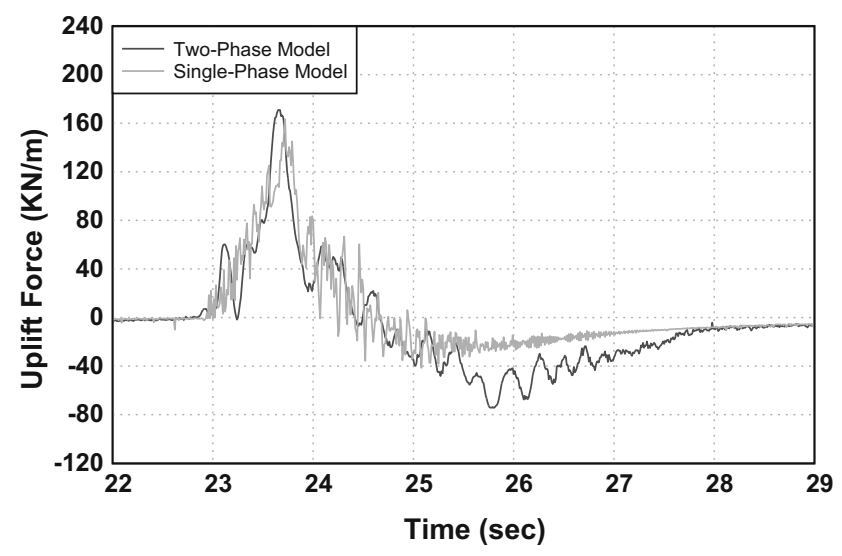

(c)

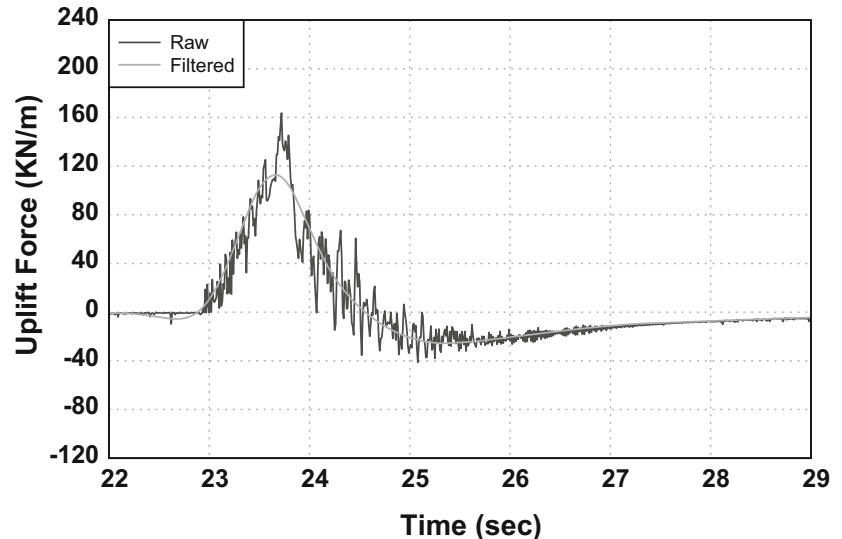

(b)

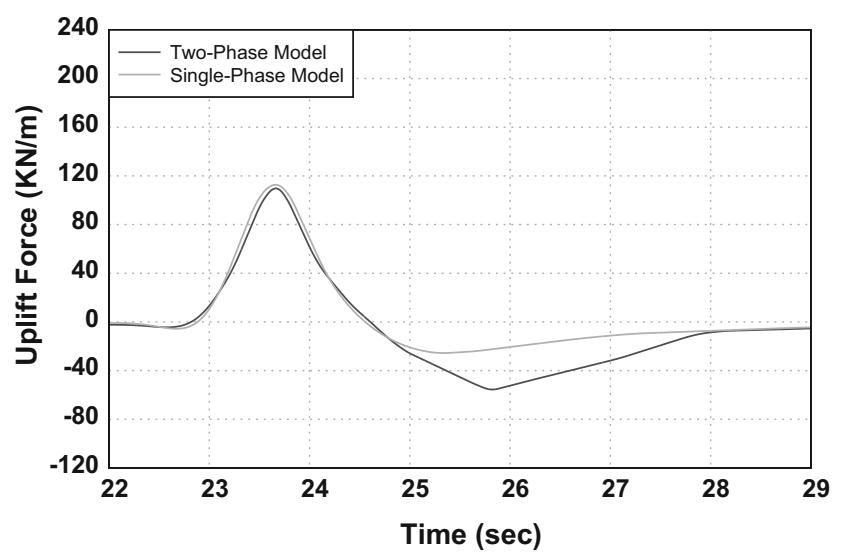

(d)

Fig. 7 Raw and filtered uplift loads from both two-phase and single-phase models and comparison between both models. a Two-phase model. b Single-phase model. $\mathbf{c}$ Raw force time histories. $\mathbf{d}$ Filtered force time histories

the bridge superstructure (see Fig. 8e). Note that the singlephase modeling of the wave field does not take the effect of the trapped air between the bridge girders into account and is not able to capture this phenomenon (see Fig. 8b). In fact, Fig. $8 \mathrm{~b}$ shows an almost perfect sinusoidal wave profile when the wave crest is under the bridge superstructure. On the other hand in two-phase simulation (Fig. 8e), the wave is completely distorted by the presence of the bridge, and the wave elevation underneath the bridge deck is flattened out due to air pressure between girders. In addition, the vertical wave loads acting on the bridge superstructure are found to be substantially higher in the case of two-phase modeling. A comprehensive comparison between the resulting wave loading of a single-phase and a two-phase numerical modeling is presented in the next section.

Figures 9 and 10 provide the results of a simulation performed for a six-girder bridge under wave loading. Figure 9 shows the hydrodynamic wave field in the left column along with the pressure plots of the trapped air between girders in the right column. The pressure plots (right column) in Fig. 9 clearly show how the air pressure changes between the bridge girders as the wave passes under the bridge. These pressure plots are computed at the middle of each chamber below the bridge deck. As the wave impacts the bridge from the left, the air pressure starts to rise when the first air chamber (Fig. 10a) experiences the maximum pressure. As the wave continues to propagate under the bridge, the air chambers between adjacent girders reach their maximum pressure sequentially. Figure 10a shows that the peak pressure in each air chamber occurs after the previous one. The overall maximum air pressure is found to occur in air chamber 2. Observe that the pressure in each air chamber gradually decreases as the wave passes under the bridge and the wave energy is dissipated through interaction with the air and interference of the viscous flow field by the fixed bridge superstructure. It also shows that there are no abrupt changes in the air pressure in the bridge chambers. Instead, the pressure varies smoothly with a gradual rise and fall pattern. The total horizontal and vertical (uplift) wave forces acting on the bridge superstructure are provided in Fig. 10b. As shown in the figure, the maximum horizontal and vertical wave forces occur at approximately the same time. The negative pressure in 
Fig. 8 Comparison of the single-phase and two-phase numerical simulations of the wave loading on bridge superstructures. a-c single-phase, $\mathbf{d}-\mathbf{f}$ two-phase simulation. a $t=23 \mathrm{~s}, \mathbf{b}$ $t=24.9 \mathrm{~s}, \mathbf{c} t=27 \mathrm{~s}, \mathbf{d}$ $t=23 \mathrm{~s}, \mathbf{e} t=24.9 \mathrm{~s}, \mathbf{f} t=27 \mathrm{~s}$

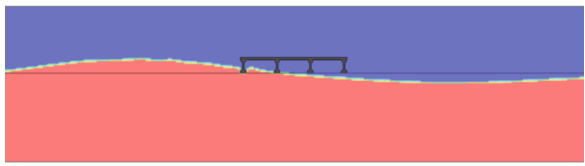

(a)

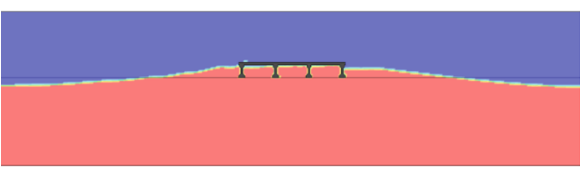

(b)

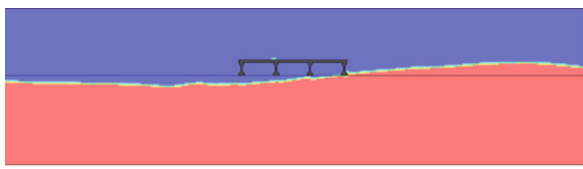

(c)

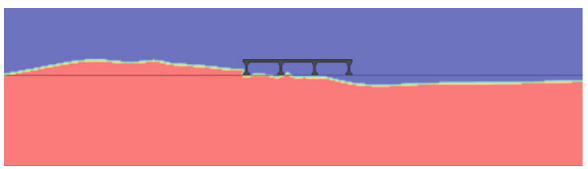

(d)

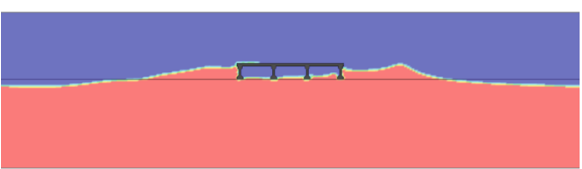

(e)

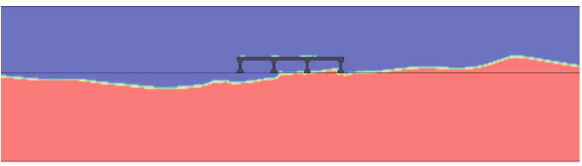

(f) chambers 3, 4, and 5 and the negative vertical force at times 22 and $26 \mathrm{~s}$ are believed to be caused by a rapid decrease in the water level under these chambers. As the wave passes, the water level under the bridge quickly drops from the low chord of the bridge girder resulting in suction of the trapped air. This is possibly due to limitation of the 2D modeling approach, as in reality air can flow into chambers from sides.

\subsection{Parametric study results}

The effect of the trapped air is investigated by comparing the resultant forces acting on the bridge superstructure in two scenarios:

1. the effect of the trapped air is taken into account in the FE model and a two-phase (air-water) simulation is carried out, and

2. the air is not modeled and a single-phase (water only) simulation is performed.

The difference between the resulting wave forces is totally attributed to the presence of the air between the bridge girders during the wave loading on the bridge superstructure. A range of wave periods, wave heights, and number of bridge girders is studied to quantify the TAE during several different wave field conditions and bridge superstructure geometries.

A constant water depth of $8 \mathrm{~m}$ is employed in all the simulations. The width (in the wave propagation direction) of all the bridges studied here is $9.7 \mathrm{~m}$. The bridge deck thickness and height of the girders are 0.25 and $1.15 \mathrm{~m}$, respectively. Spacing between the bridge girders varies from 1.42 to $2.64 \mathrm{~m}$ depending on the number of girders. The low chord elevation of the bridge, defined as the elevation of the bottom of the bridge girders, is set at the still water level to maximize the TAE.

Both the water and the air domains are modeled as compressible flows. The mass densities of water and air are 1000 and $1.2 \mathrm{~kg} / \mathrm{m}^{3}$, respectively. The computational domain is constructed using eight-node hexahedron solid elements. The mesh size and the computational time step are $125 \mathrm{~mm}$ and $3 \mathrm{E}-4 \mathrm{~s}$, respectively. The time step was approximately ten times smaller for the validation study simulations due to smaller bridge geometry and smaller mesh size in the computational domain. It also should be stated that no mesh gradation was utilized in this study. The number of elements is approximately 150,000 in the $2 \mathrm{D}$ models, while this number goes up to 893,000 and $1,787,000$ for the two 3D models developed to study air ventilation effect. A comparison between the numerical simulation results with the original time step (3E-4 s) and simulations with ten times smaller time step showed no noticeable difference in the results. This is because the original time step is chosen to be sufficiently small and convergence has been achieved. Typical simulation clock times are in the order of 1-3 days.

It is assumed that the bridge is supported by transverse diaphragms which are as deep as the longitudinal girders. This assumption along with setting the low chord elevation of the bridge at the still water level maximizes the TAE. The diaphragms block any transverse movement of the entrapped air between bridge girders, thus making a 2D modeling of the wave-bridge superstructure interaction including the TAE reasonable.

Figure 11 shows the numerical results of the four-girder bridge under different wave field conditions with and without the TAE. Note that there is a substantial (up to an order of magnitude) difference between the vertical wave forces 


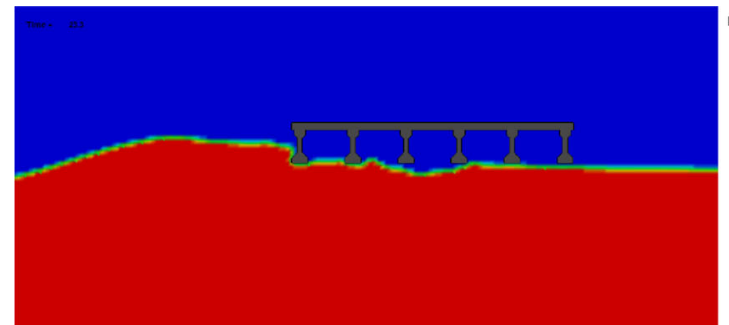

(a)

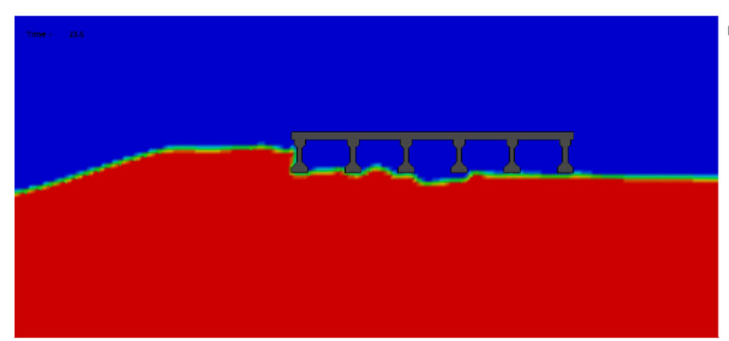

(b)

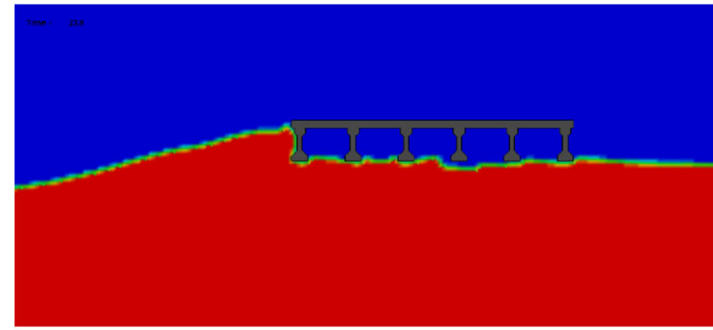

(c)

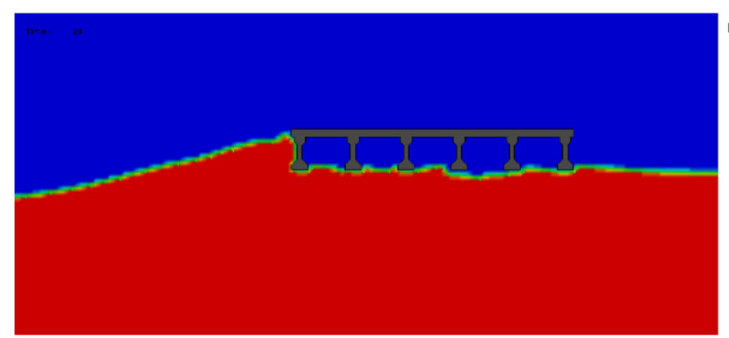

(d)

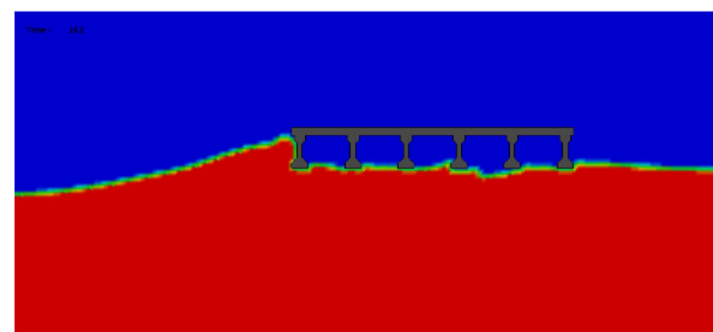

(e)

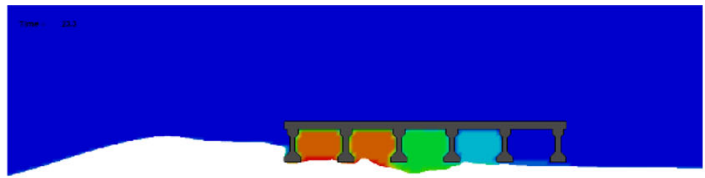
$5.417 \mathrm{e}-03$ $4.855 e-03$

730003 $3.168 \mathrm{e}-03$ 2.605e-03 2.043e- 03 $1.480 \mathrm{e}-03$ 9.181e-04 $3.556 \mathrm{e}-04$

(f) Fringe Levels
$1.000 \mathrm{e}+00$
$9.000 \mathrm{e}-01]$
$8.000 \mathrm{e}-01]$
$7.000 \mathrm{e}-01]$
$6.000 \mathrm{e}-01$
$5.000 \mathrm{e}-01$
$4.000 \mathrm{e}-01$
$3.000 \mathrm{e}-01$
$2.000 \mathrm{e}-01$
$1.000 \mathrm{e}-01$
$0.000 \mathrm{e}+00$

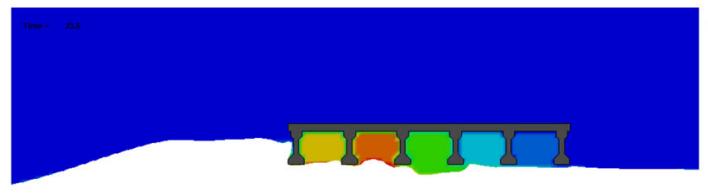

ringe Levels $6.248 \mathrm{e}-03$ 5.612e-03 $4.975 e-03$ 4.338e-03_ 3.701e-03 3.064e- 03 2.427e-03 $1.790 \mathrm{e}-03$ 1.154e-03 5.167e-04

(g)
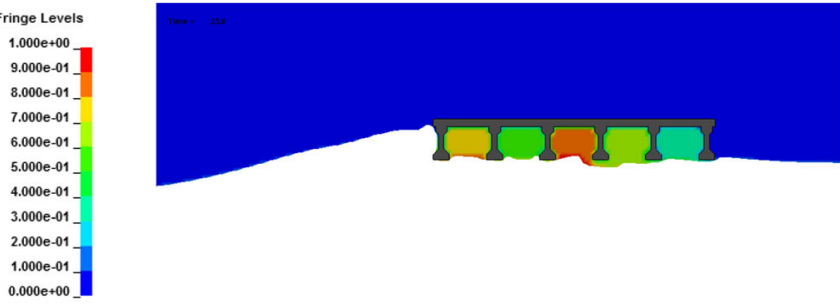

ringe Levels $5.196 \mathrm{e}-03$ $4.666 \mathrm{e}-03$ 4.136e-03 $3.606 \mathrm{e}-03$ $3.076 \mathrm{e}-03$ $2.547 \mathrm{e}-03$ $1.487 \mathrm{e}-03$ 9.573e-04 $4.275 \mathrm{e}-04$

(h) Fringe Levels
$1.000 \mathrm{e}+00$
$9.000 \mathrm{e}-01]$
$8.000 \mathrm{e}-01$
$7.000 \mathrm{e}-01$
$6.000 \mathrm{e}-01$
$5.000 \mathrm{e}-01$
$4.000 \mathrm{e}-01$
$3.000 \mathrm{e}-01$
$2.000 \mathrm{e}-01$
$1.000 \mathrm{e}-01$
$0.000 \mathrm{e}+00$

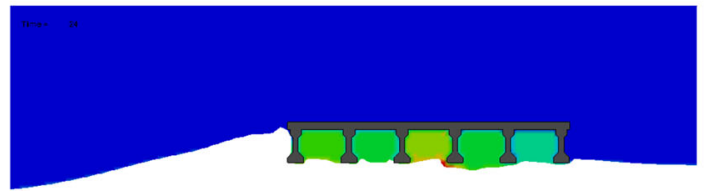

Fringe Levels $6.180 \mathrm{e}-03$ $5.546 e-03$ $4.913 \mathrm{e}-03$ $4.279 \mathrm{e}-03$ $3.646 \mathrm{e}-03$ $3.012 \mathrm{e}-03$ $2.378 \mathrm{e}-03$ $1.745 \mathrm{e}-03$ 1.111e-03 $4.775 \mathrm{e}-04$

(i)
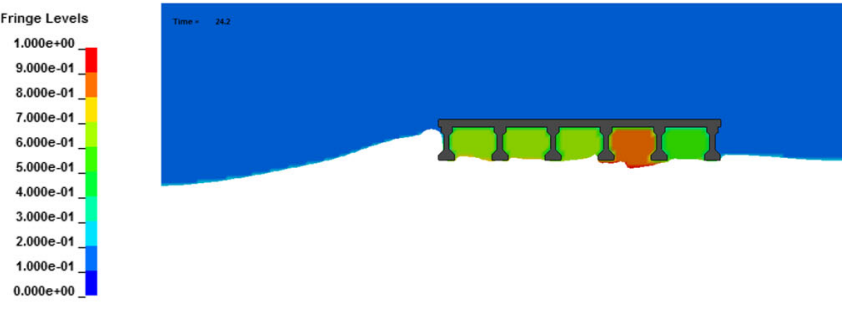

Fringe Levels $4.304 \mathrm{e}-03$ 3.799e-03 3.294e-03 $2.789 \mathrm{e}-03$ 2.284e- 03 $1.779 \mathrm{e}-03$ $1.274 \mathrm{e}-03$ $7.685 \mathrm{e}-04$ $2.635 \mathrm{e}-04$ $2.416 \mathrm{e}-04$

(j)

Fig. 9 Comparison of air pressure between bridge girders during wave passage. a $t=23.3 \mathrm{~s}, \mathbf{b} t=23.5 \mathrm{~s}, \mathbf{c} t=23.9 \mathrm{~s}, \mathbf{d} t=24 \mathrm{~s}, \mathbf{e} t=24.2 \mathrm{~s}, \mathbf{f}$ $t=23.3 \mathrm{~s}, \mathbf{g} t=23.5 \mathrm{~s}, \mathbf{h} t=23.9 \mathrm{~s}, \mathbf{i} t=24 \mathrm{~s}, \mathbf{j} t=24.2 \mathrm{~s}$ 


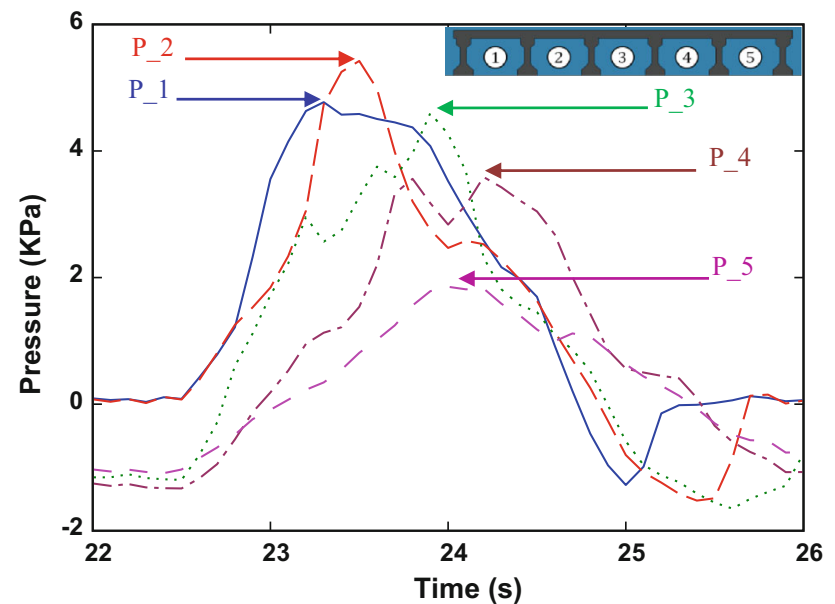

(a)

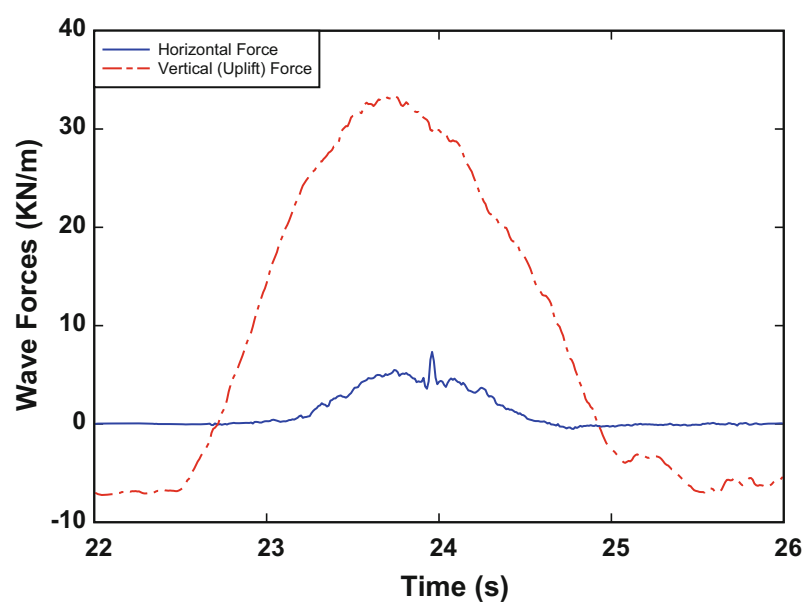

(b)

Fig. 10 a Pressure in air chambers between adjacent bridge girders, and $\mathbf{b}$ total horizontal and vertical wave forces acting on the bridge superstructure

obtained from the two cases. The no TAE case resulted in approximately $88 \%$ smaller maximum vertical (uplift) wave forces compared to the case including the effect of the trapped air between the bridge girders when the wave period is $4 \mathrm{~s}$. For larger wave periods of 6 and $8 \mathrm{~s}$, the maximum vertical wave forces are found to be, on average, 75 and $63 \%$ smaller, respectively, when the TAE is neglected in the simulations. For the five- and six-girder bridge models, this TAE is slightly lower. For the wave periods of 4,6 and $8 \mathrm{~s}$, the maximum vertical wave forces on the five-girder bridge, on average, are 86,75 , and $59 \%$ smaller, respectively, when the TAE is neglected in the simulations (see Fig. 12). Results also show that for the wave periods of 4,6 and $8 \mathrm{~s}$, the maximum vertical wave forces on the six-girder bridge, on average, are 79,73 , and $57 \%$ smaller, respectively, when the effect of the trapped air is neglected in the simulations (see Fig. 13).

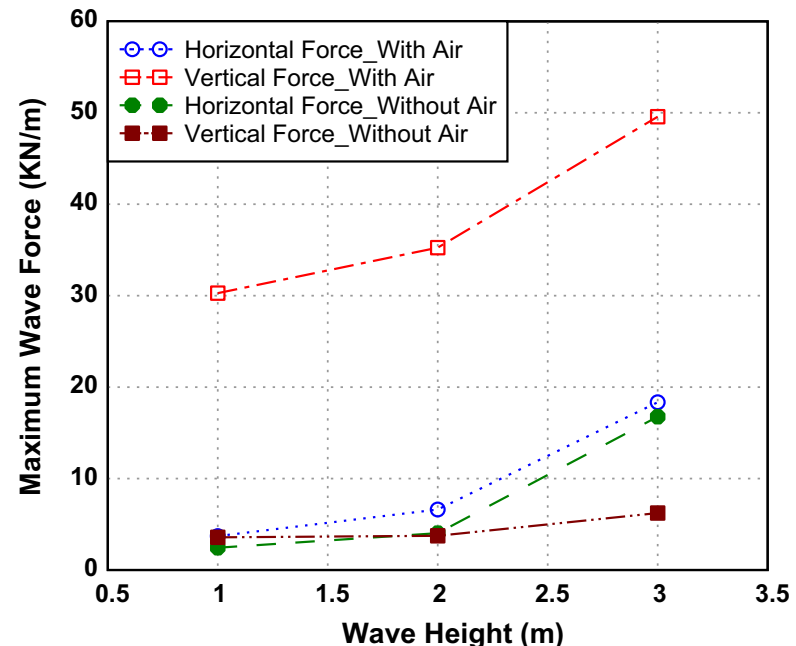

(a)

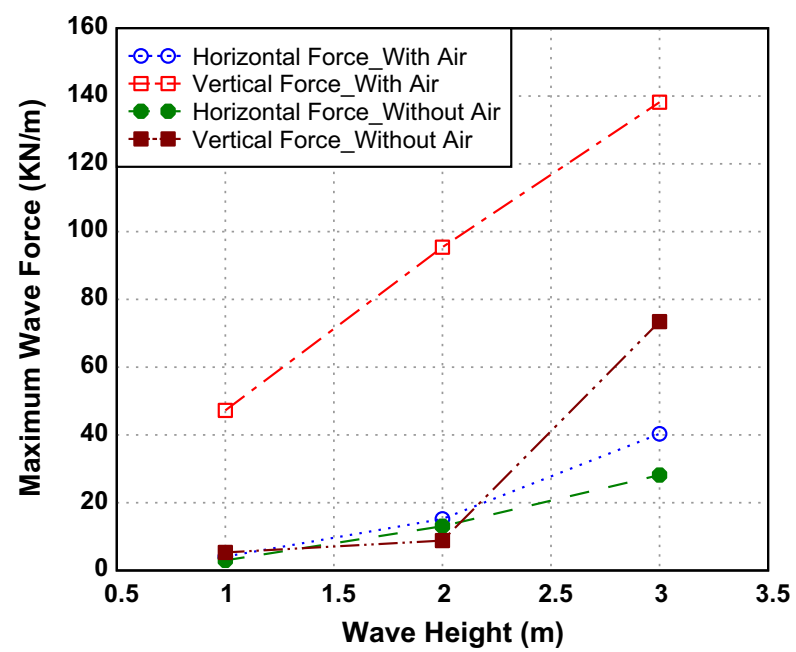

(b)

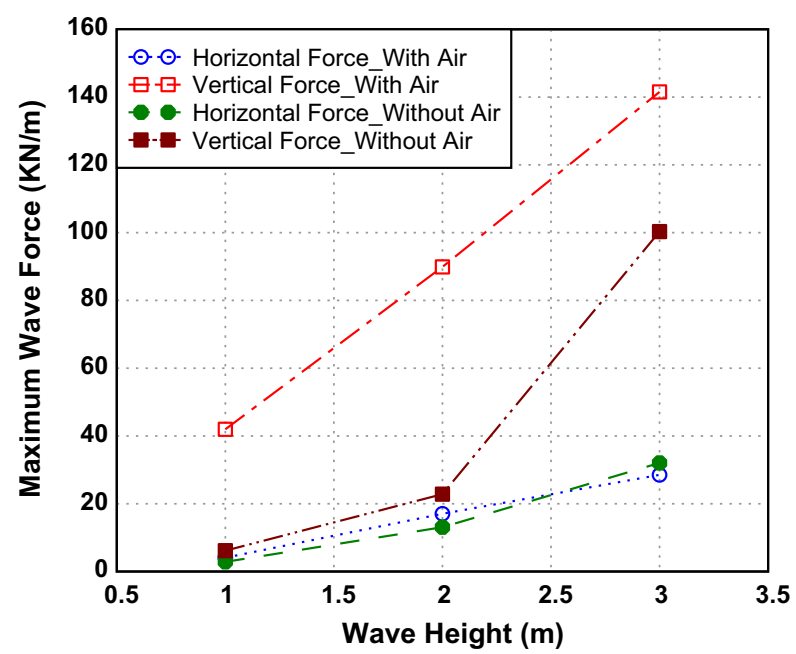

(c)

Fig. 11 Maximum wave forces acting on the four-girder bridge model for different wave conditions. a 4-girder bridge, wave period $=4 \mathrm{~s}$. b 4-girder bridge, wave period $=6 \mathrm{~s}$. $\mathbf{c} 4$-girder bridge, wave period $=8 \mathrm{~s}$ 


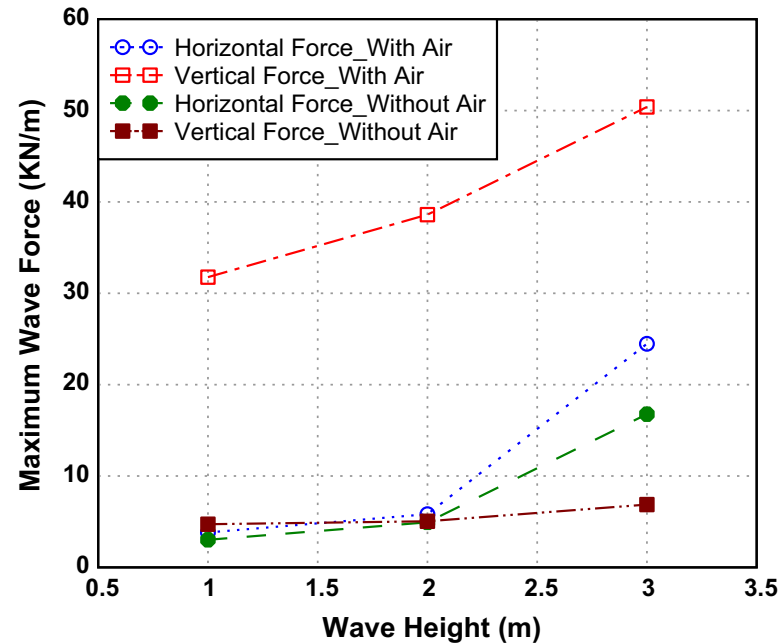

(a)

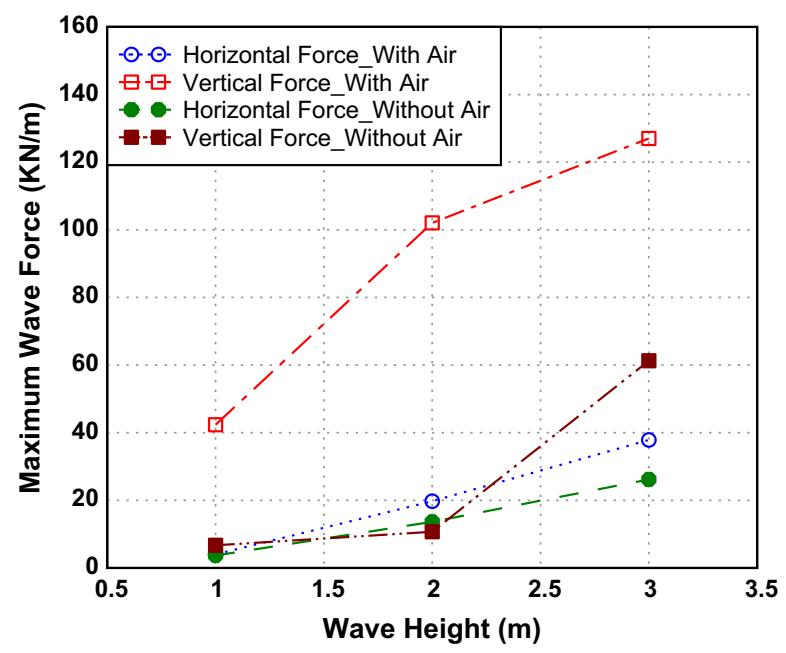

(b)

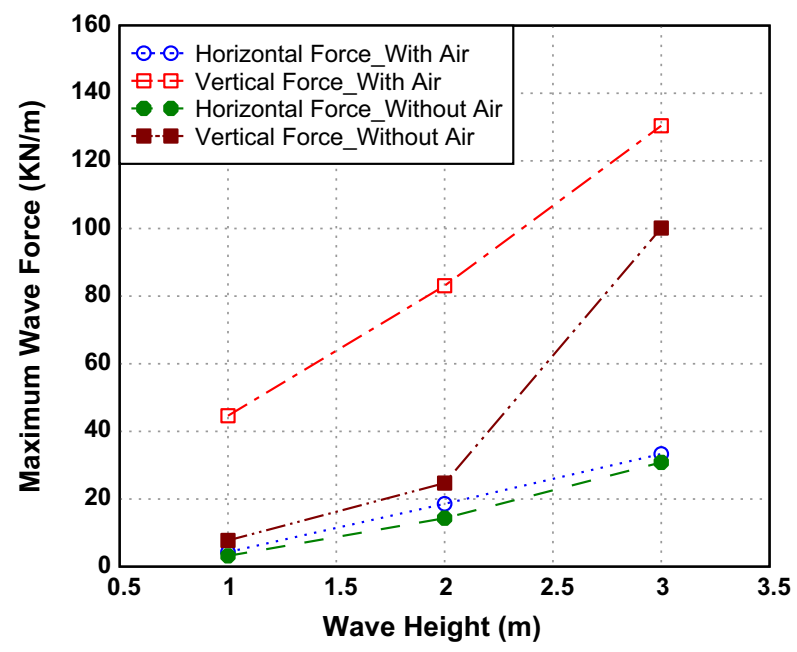

(c)

Fig. 12 Maximum wave forces acting on the five-girder bridge model for different wave conditions. a 5-girder bridge, wave period $=4 \mathrm{~s}$. b 5 -girder bridge, wave period $=6 \mathrm{~s}$. c 5 -girder bridge, wave period $=8 \mathrm{~s}$

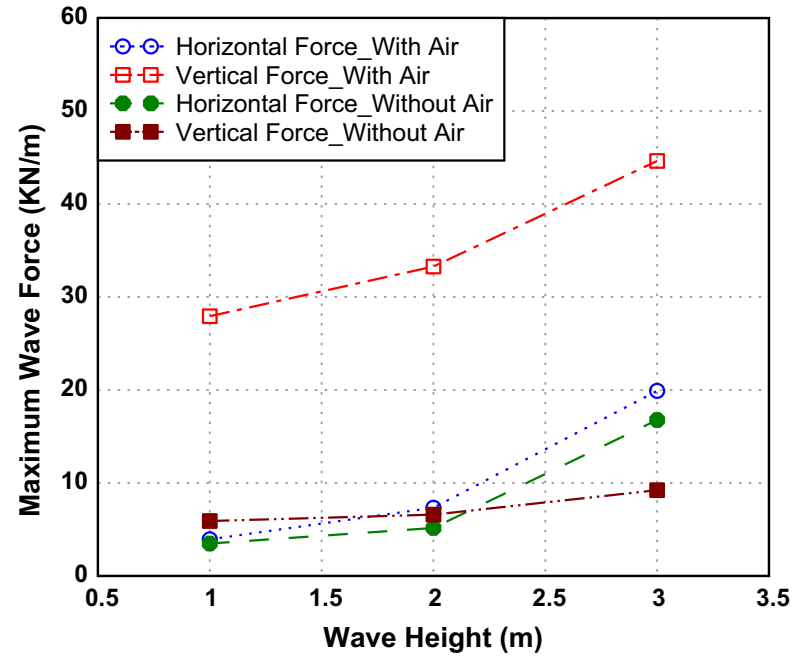

(a)

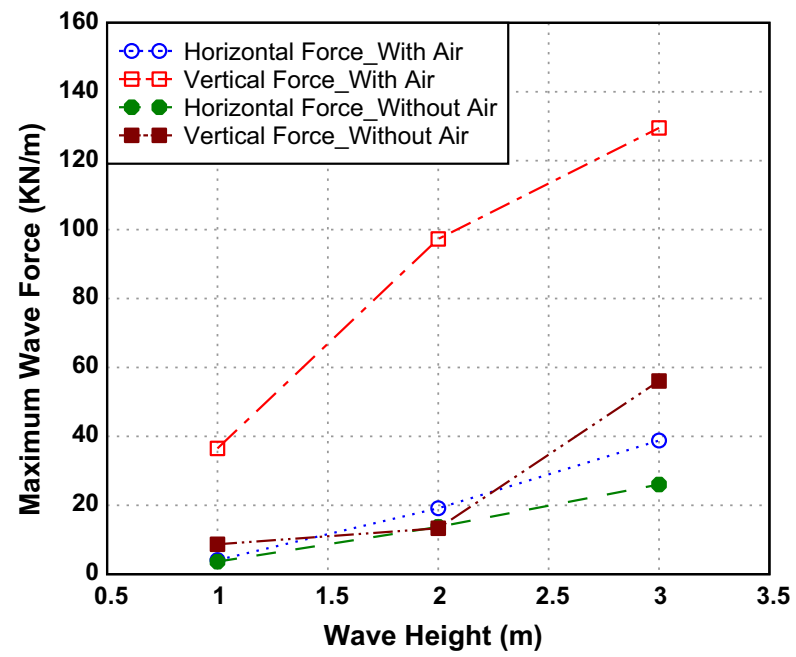

(b)

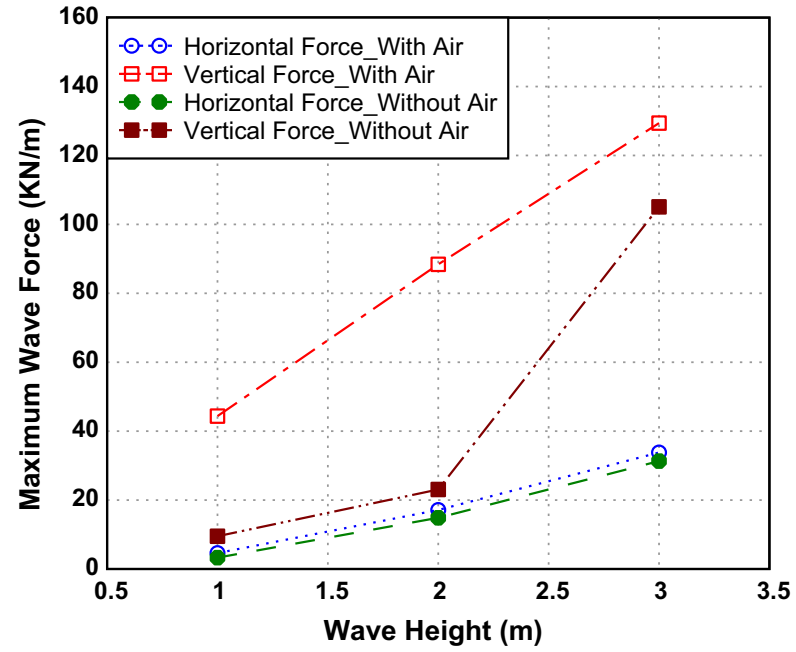

(c)

Fig. 13 Maximum wave forces acting on the six-girder bridge model for different wave conditions. a Wave period $=4 \mathrm{~s}$. b Wave period $=6$ s. $\mathbf{c}$ Wave period $=8 \mathrm{~s}$ 
The results suggest that the presence of trapped air is important in increasing the vertical wave force, especially for wave conditions in which the waves do not reach the bridge deck. Note that, with no bridge model clearance (i.e., SWL right at the bottom of the girders), only waves with $3 \mathrm{~m}$ height can reach the bottom of the bridge deck. Hence, in situations where waves are not sufficiently high to reach the bridge deck, the vertical force is mainly a result of buoyancy force during the passage of the wave under the bridge superstructure. On the other hand, when the presence of the air is neglected, since the wave crest does not reach the bridge deck, a minimal vertical force is exerted on the bridge superstructure due to wave impact and buoyancy on the girders that push the bridge superstructure upward. In scenarios where the wave height is $3 \mathrm{~m}$ and wave period is either 6 or $8 \mathrm{~s}$, waves can reach the bridge deck. In these situations, the difference between single-phase and two-phase simulations is smallest as the effect of trapped air is minimal.

Another important factor which influences the effect of the trapped air on the vertical wave force acting on bridge superstructures is the wave period. According to the simulation results provided in Figs. 11, 12 and 13, the TAE is higher for the waves with a relatively shorter period. It is found that the magnifying effect due to the presence of the trapped air decreases with increasing wave period.

A comparison between the maximum horizontal forces acting on the bridge models in the two different cases, with and without TAE, reveals that the maximum horizontal forces tend to be slightly lower when the effect of the trapped air is neglected. Although a consistent pattern is not observed in the reduction of the maximum horizontal force because of neglecting the presence of the trapped air between the bridge girders, this decrease in horizontal forces is relatively higher for wave conditions in which the wave period is shorter (corresponding to shorter wave length).

\section{Effect of trapped air on vertical wave force of bridge superstructure}

A parametric study was conducted to evaluate the effect of the trapped air between bridge girders on the magnitude of the wave forces acting on the bridge superstructures. The numerical simulation results show that the presence of the air trapped between the bridge girders increases the maximum vertical (uplift) forces acting on the bridge models. However, the degree of effectiveness of the trapped air varies with the range of wave periods, wave heights, and number of bridge girders. An accurate estimation of the TAE is very useful in predicting the wave forces on bridge superstructures as well as in deploying countermeasures to reduce the total wave force by decreasing the effect of trapped air. To further examine this effect in a systematic way, a dimensionless trapped air effect parameter $\psi_{\mathrm{TAE}}$ is introduced as follows:

$\psi_{\mathrm{TAE}}=\frac{F_{V \text { Two-phase }}-F_{V \text { Single-phase }}}{F_{V \text { Two-phase }}} \times 100 \%$,

where $\psi_{\mathrm{TAE}}$ is the trapped air effect (TAE) parameter; $F_{V \text { Two-phase }}$ is the vertical wave force computed from the two-phase numerical simulation considering the TAE; and $F_{V \text { Single-phase }}$ is the vertical wave force computed from the single-phase numerical simulation not considering the TAE.

The TAE parameter, $\psi_{\mathrm{TAE}}$, is designed to show the degree of effectiveness of the trapped air between bridge girders in increasing the vertical (uplift) wave force acting on a bridge superstructure considering various wave periods, wave heights, and number of bridge girders. The values of the $\psi_{\mathrm{TAE}}$ for different bridge geometries as well as various wave conditions are shown in Fig. 14 for four-, five-, and six-girder bridge models. Note that the value of the TAE parameter, $\psi_{\mathrm{TAE}}$, is sensitive to both wave heights and wave periods and less sensitive to the number of girders supporting the bridge deck. However, $\psi_{\mathrm{TAE}}$ is relatively constant when the wave period is $4 \mathrm{~s}$ regardless of the height of the wave and the number of girders.

Although $\psi_{\mathrm{TAE}}$ is found to be sensitive to the wave period such that it decreases as the wave period increases, it is most sensitive to the wave height among different factors studied in this research. The degree of sensitivity of $\psi_{\mathrm{TAE}}$ to wave height is highly influenced by the wave period. Results reveal that $\psi_{\mathrm{TAE}}$ is less sensitive to changes in the wave height for shorter wave periods, while the reduction in $\psi_{\mathrm{TAE}}$ could be dramatic as the wave height with longer period increases. This means that when the wave height and period increase simultaneously, the effect of the trapped air between bridge girders experiences a significant decline.

\section{Effect of bridge-deck ventilation on vertical wave forces}

A set of numerical simulations using three-dimensional (3D) models of the bridge superstructure is conducted to assess the effectiveness of venting the bridge deck in reducing the vertical wave forces on bridge superstructures. 3D models are needed because the air vents are small in dimension compared with the length of the deck and the air flow behavior varies significantly in the longitudinal direction of the bridge deck (parallel to the girders), thus making the venting effect local and three dimensional. A selected number of air vents were positioned at the down-wave end of the bridge deck spans to examine their capability in reducing the vertical wave forces. Figure 15a, b shows the bridge cross-sectional geometry and overall configuration. Figure $15 \mathrm{c}$ shows the two strips used for FE modeling. The vent area is $3 \%$ of the 


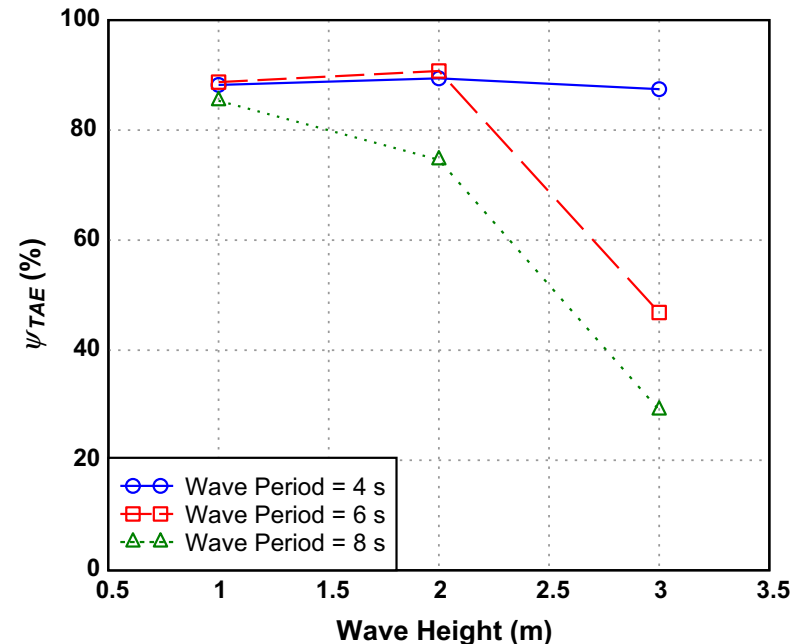

(a)

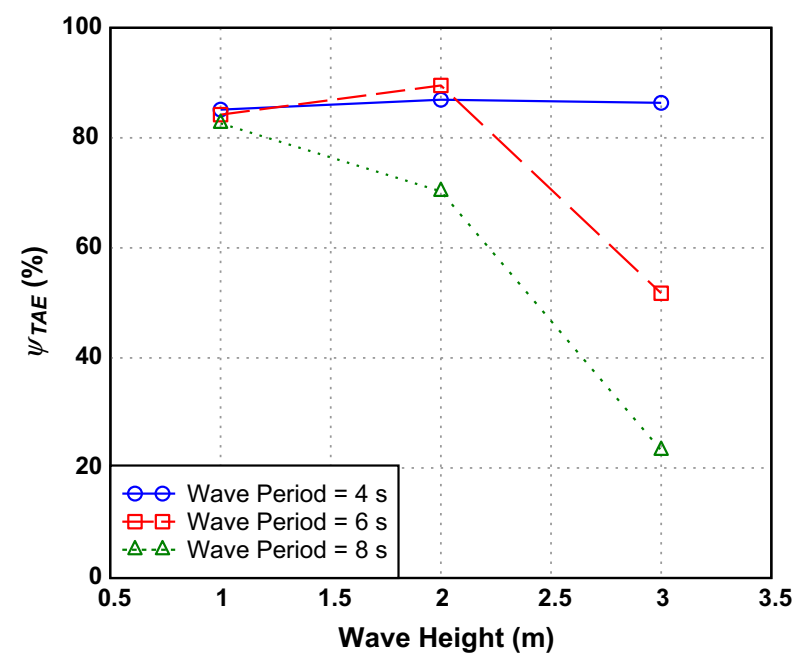

(b)

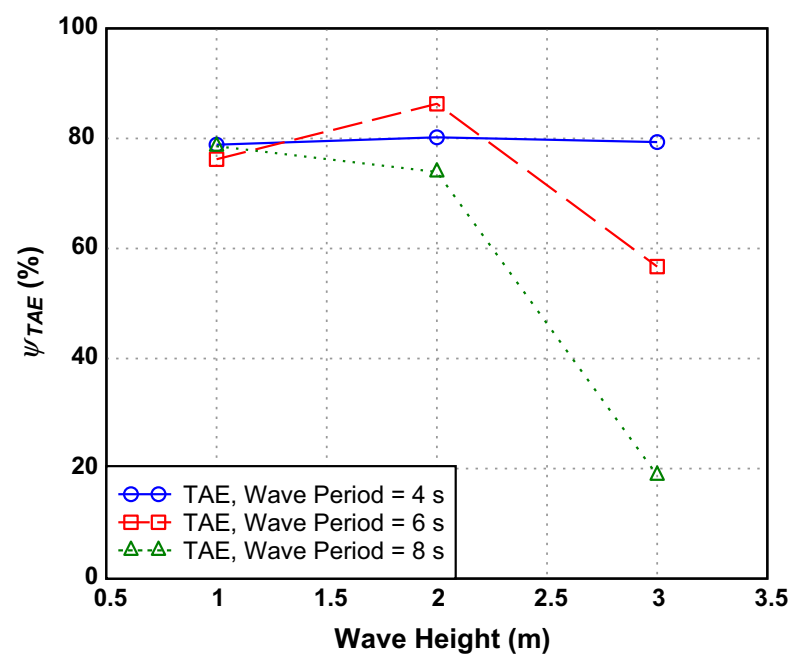

(c)

Fig. 14 Comparison of the TAE parameter for different bridge geometries and wave conditions. a 4-girder bridge model. b 5-girder bridge model. c 6-girder bridge model area of the bridge deck in modeling. As shown in Fig. 15c, the center strip is bounded between centerlines of two adjacent vent rows (solid yellow lines), whereas the end strip is bounded between bridge diaphragms and the centerline of two external vent rows (dashed black lines). Due to the presence of the diaphragms, these centerlines are symmetry planes where ideally there is no transverse movement of the air. The total wave uplift force on the vented bridge deck is obtained by three times the force on the center strip and two times the force on end strips normalized by the total length of the span between diaphragms to obtain an equivalent uplift force per unit length of bridge superstructure.

Figure 16 depicts the velocity vector plots of the center strip of the 3D model of the bridge superstructure. For this particular simulation, the wave height and wave period are $1 \mathrm{~m}$ and $4 \mathrm{~s}$, respectively. The snapshots in Fig. 16 show the velocity plot when the maximum uplift force occurs, and how the trapped air is released through the air vents which ultimately leads to a lower uplift wave force on the bridge superstructure. Note the water free-surface rise between the bridge girders due to the partial evacuation of the trapped air from the chamber through the vents. Time histories of the uplift forces on both 3D models of center and end strips of the vented bridge are shown in Fig. 17a. The normalized uplift force (per unit length) on the vented superstructure is compared with the corresponding uplift force on the intact bridge (without ventilation) in Fig. 17b. The normalized force on the vented bridge is calculated using the equation, $F_{\text {Normalized }}=\frac{3 \times F_{\text {Center Strip }}+2 \times F_{\text {End Strip }}}{\text { Bridge Length }}$. Note the oscillations in the uplift force are more noticeable when the bridge deck is vented. This is due to the presence of the vents which help sequentially release the trapped air in adjacent chambers between bridge girders.

Figure 18 presents the results of the numerical simulations conducted using the 3D model of the vented bridge deck in comparison with cases where the trapped air effect is either totally included or neglected in analyses using the 2D models presented earlier. The five-girder bridge model is used for a series of numerical simulations. Results are provided here for three selected wave periods of 4,6 , and $8 \mathrm{~s}$ as well as for three wave heights 1,2 , and $3 \mathrm{~m}$.

Figure 18 shows a significant reduction in the uplift wave forces on the vented bridge deck, with the vertical wave forces decreased by $56 \%$ on average for all three wave periods studied here. This reduction is higher for the shortest wave period which is $63 \%$. The average reductions in the uplift force are 55 and $50 \%$ when the wave periods are 6 and $8 \mathrm{~s}$, respectively. These results suggest that the uplift wave forces acting on the bridge superstructure can be reduced substantially using air vents. This reduction can be further enhanced by increasing the size of the vents. 
Fig. 15 a Bridge deck without ventilation, $\mathbf{b} 3 \mathrm{D}$ model of bridge deck supported by bents, c location of bridge deck vents, d 3D FE model of the middle strip, e 3D FE model of the end strip (color figure online)
Direction of wave propagation

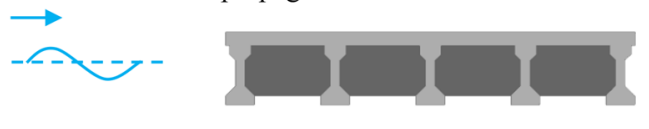

(a)

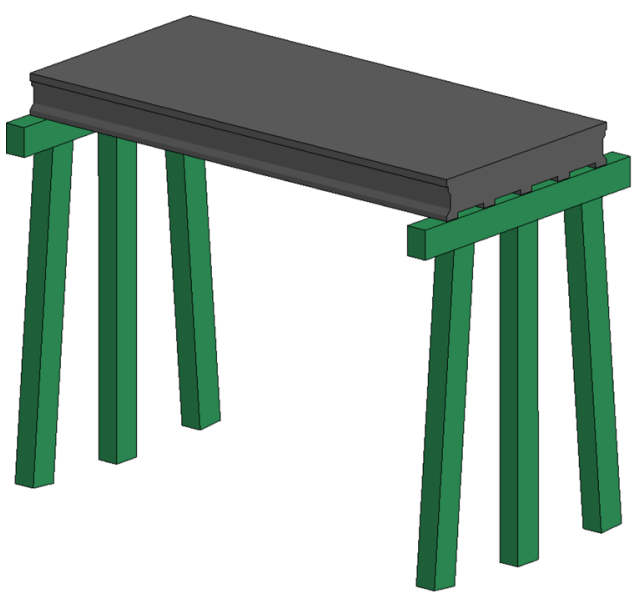

(b)

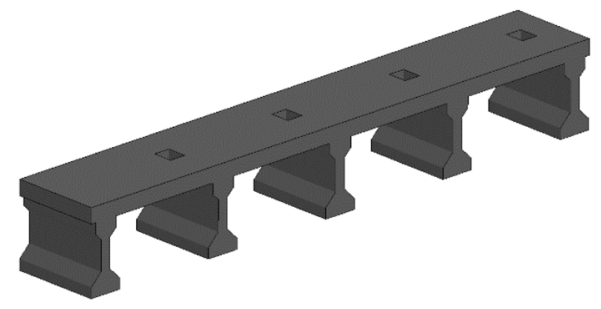

(d)

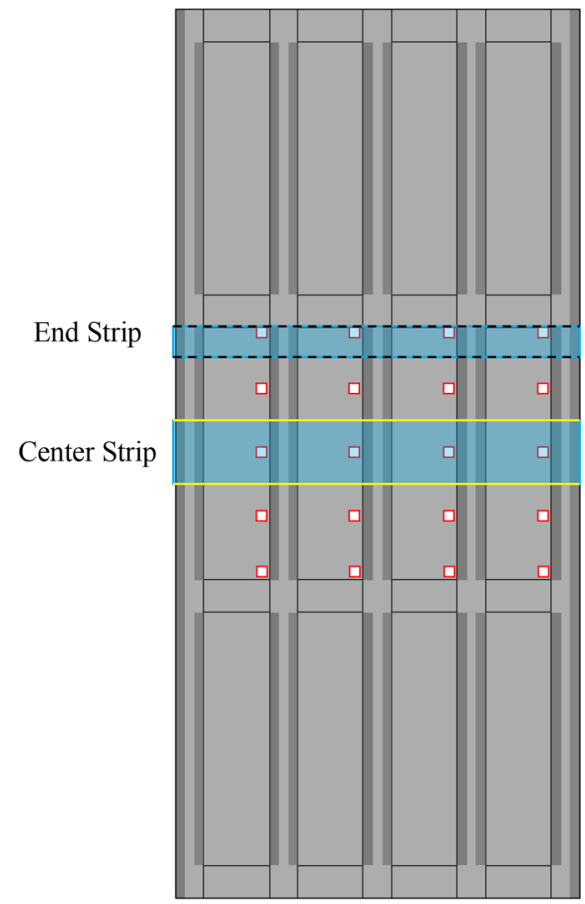

(c)

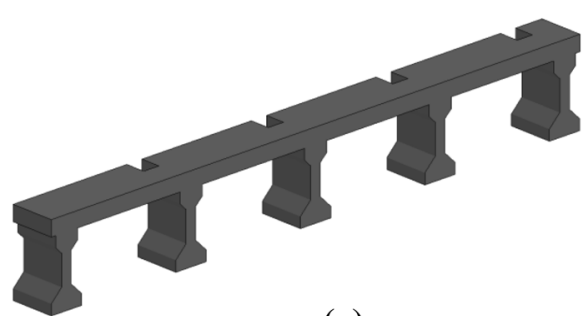

(e)
Based on the numerical results presented above, we may state that the use of vents would have similar load reduction effect on wave forces experienced by coastal bridges during Hurricane Katrina. However, additional modeling and simulation efforts are needed to confirm this conjecture.

\section{Comparison with AASHTO recommendations}

The American Association of State Highway and Transportation Officials (AASHTO 2008, Sections 6.1.2.2, 6.1.2.3) provide a set of design expressions to estimate the wave forces on coastal bridges. Estimations of the maximum horizontal wave force and the vertical wave force are provided along with their associated vertical and horizontal component, respectively. The maximum horizontal and vertical forces are expressed in US customary units as follows:

$$
\begin{aligned}
& F_{\text {H-MAX }}=\gamma_{w} \pi\left(d_{b}+r\right)\left(\omega+\frac{1}{2} H_{\max }\right)\left(\frac{H_{\max }}{\lambda}\right) \\
& \times \operatorname{Exp}\left\{-3.18+3.76 e^{\left(-\frac{\omega}{\lambda}\right)}-0.95\left[\ln \left(\frac{\eta_{\max }-z_{c}}{d_{b}+r}\right)\right]^{2}\right\} \\
& F_{\mathrm{V}-\mathrm{MAX}}=\gamma_{w} \overline{\mathrm{W}} \beta\left(-1.3 \frac{H_{\max }}{d_{s}}+1.8\right) \\
& \quad \times\left[1.35+0.35 \tanh \left(1.2\left(T_{p}\right)-8.5\right)\right] \\
& \quad \times\left(b_{0}+b_{1} x+\frac{b_{2}}{y}+b_{3} x^{2}+\frac{b_{4}}{y^{2}}+\frac{b_{5} x}{y}+b_{6} x^{3}\right)(\mathrm{TAF}),
\end{aligned}
$$

where $F_{\text {H-MAX }}$ is the maximum quasi-static horizontal force $(\mathrm{Kip} / \mathrm{ft}) ; F_{\text {V-MAX }}$ is the maximum quasi-static vertical force $(\mathrm{Kip} / \mathrm{ft}) ; \gamma_{w}$ is the unit weight of water taken as 0.064 $\left(\mathrm{Kip} / \mathrm{ft}^{3}\right) ; \bar{W}$ is a parameter defined based on wave length, 
Fig. 16 a Front and $\mathbf{b}$ oblique view of the velocity vector plot

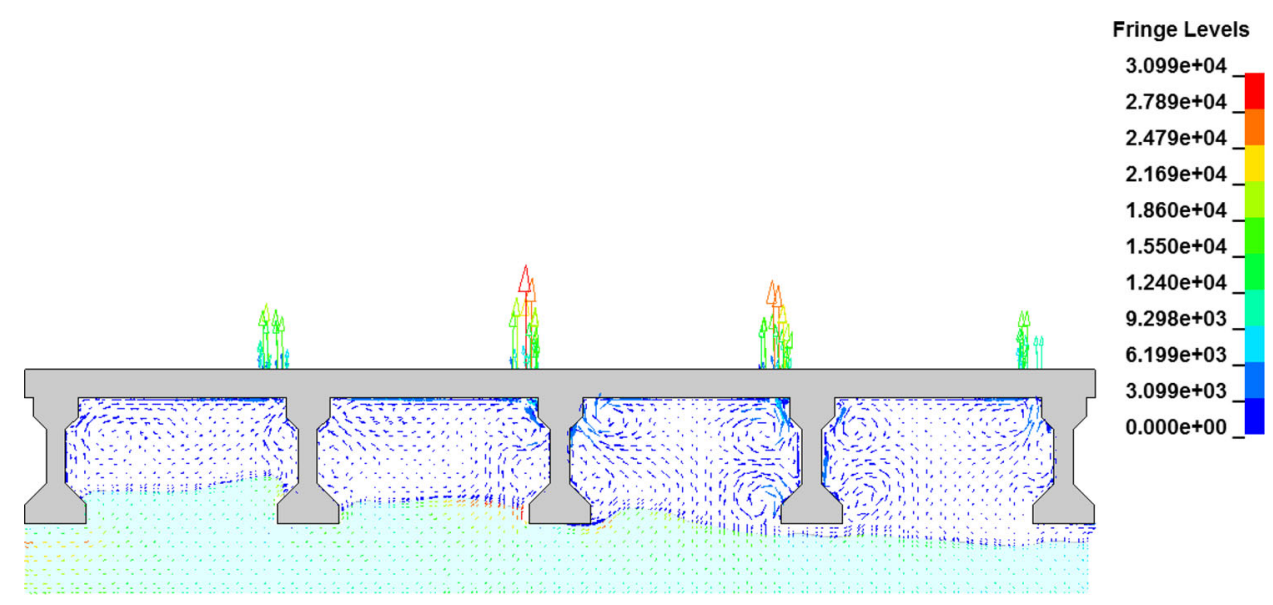

(a)

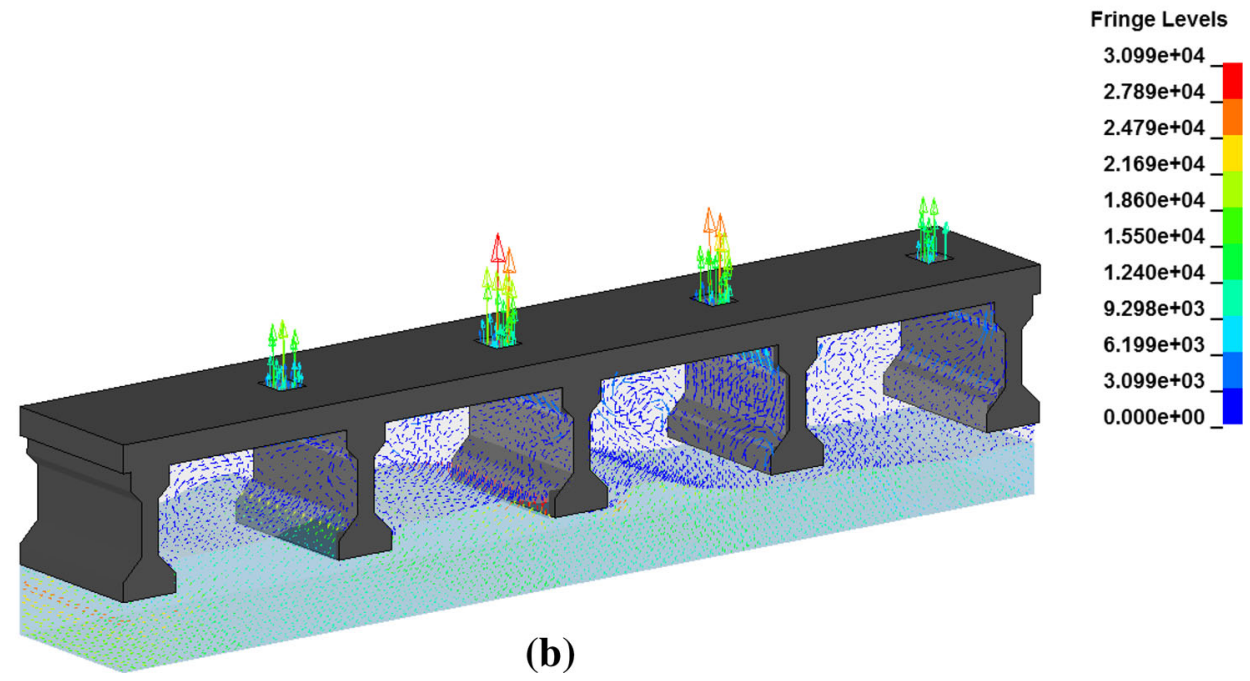

wave height, and bridge clearance (ft); $\eta_{\max }$ is the distance from the storm water level to design the wave crest (ft); $H_{\max }$ is the maximum probable wave height (ft); $T_{p}$ is the period of the waves with the greatest energy $(s) ; \lambda$ is the wavelength $(\mathrm{ft}) ; d_{s}$ is the storm water depth $(\mathrm{ft}) ; d_{b}$ is the girder height plus slab thickness (ft); $r$ is the rail height (ft); $\omega$ is a parameter defined based on wavelength, wave height, and bridge clearance (ft); $b_{0-6}$ is the empirical variables defined based on bridge girder height; $x$ is a parameter defined based on wavelength and wave height; $y$ is a parameter defined based on wavelength, wave height, and bridge clearance; TAF is the trapped air factor.

The design expression for the maximum quasi-static vertical force accounts for different degrees of air entrapment between bridge girders (AASHTO 2008). The parameter TAF in Eq. 11 is computed based on the percentage of the air trapped between bridge girders during the passage of the design wave. This trapped air percentage is referred to as \%AIR in AASHTO (2008). The \%AIR depends on the wave crest elevation as well as the girder height and the bridge clearance from the storm water level. AASHTO (2008) recommends the minimum and maximum values for the parameter \%AIR based on the relative height of the bridge girders to the supporting diaphragms.

In spite of these recommendations, the final decision on the amount of this parameter to be used in wave force calculations is left to the designer. Therefore, the numerical results of the vertical wave forces on the intact bridge obtained from the computational analyses in this study are compared to design expression estimations with the trapped air parameter \%AIR ranging from 0 to $100 \%$. Figure 19 shows a comparison of the horizontal and vertical wave forces from numerical simulations, with the range of the maximum vertical force due to the change in the parameter \%AIR shown as the shaded area. Note that the design expression of the maximum quasistatic vertical force can lead to an underestimation of the forces for waves with relatively small wave heights. In these 
Fig. 17 a Uplift wave forces on two 3D models and $\mathbf{b}$ comparison of uplift wave forces on intact and vented bridges

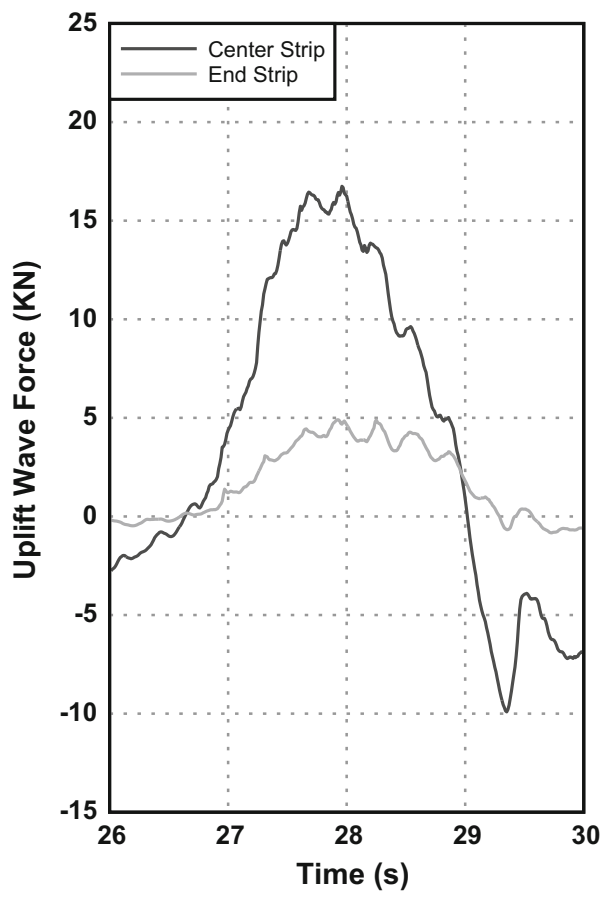

(a)

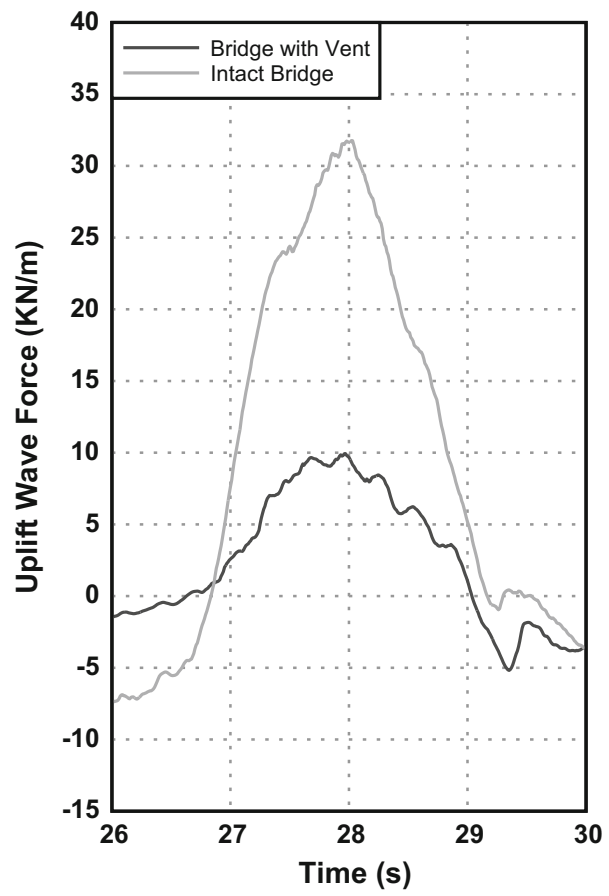

(b) cases, the formula estimation of the wave force considering the maximum \%AIR could underestimate the vertical force up to $100 \%$, while the amount of underestimation is lower for other wave field conditions. On the other hand, for larger wave heights, use of the maximum \%AIR value could result in a substantial overestimation of the vertical force. As shown in Fig. 19, this overestimation could be up to $200 \%$ for some cases. This indicates that there is room for improvement in determining the \%AIR to provide a better estimation of the wave forces on bridge superstructures.

A comparison of the numerical calculations of the horizontal wave forces against maximum quasi-static forces estimations of AASHTO for various wave periods, wave heights, and bridge superstructure geometries is also provided in Fig. 19. As shown in the figure, the design expression of the maximum horizontal force could lead to a reasonable estimation of the wave forces on bridge superstructures. It is found that the design expression of maximum horizontal force could overestimate the wave force for relatively short period waves.

It is noted that systematic studies on fluid impact effect on bridge superstructures due to tsunami loads have recently been presented (Yim et al. 2014a,b; Azadbakht and Yim 2014, 2015). However, the load characteristics of tsunamis, which are highly transient and bore-like, may be significantly different than those of wind-generated waves. Thus, results on the effect of trapped air presented here may not be directly extensible to those of tsunamis. Separate independent experimental and numerical studies will need to be conducted.

\section{Concluding remarks}

A comprehensive study was conducted to evaluate the effect of trapped air in increasing the vertical wave forces on coastal bridge superstructures. A range of wave conditions, i.e., wave period and wave height, was studied as well as different bridge superstructure geometries. The effect of the trapped air was assessed by comparing the numerical results of singlephase (water) and two-phase (air-water) flow simulations. Single-phase simulations represent the situation where the air trapped between the bridge girders has no effect on the wave forces on the bridge and imposes no resistance against waves striking the bottom of the bridge deck from below. The two-phase simulations provide a simulation considering real properties of air and water. The effectiveness of the bridge deck vents in reducing the uplift forces caused by the trapped air between bridge girders (i.e., the trapped air effect) was investigated. The numerical results of the computational analyses of the wave forces on coastal bridge superstructures were also compared to estimations from the AASHTO design expressions. The following are the findings of the presented study:

- It was clearly shown that, in the case of having diaphragms as deep as the bridge girders (e.g., experimental setup in Bradner 2008), the trapped air behaviors in each section in the cross flow direction (i.e., normal to the wave propagation direction) are practically identical. This is due to the fact that the diaphragms block the transverse (cross 


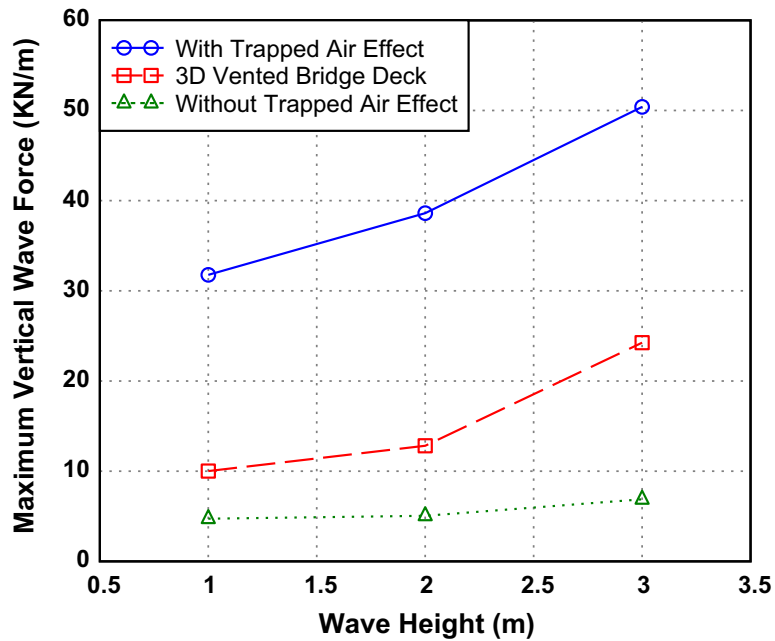

(a)

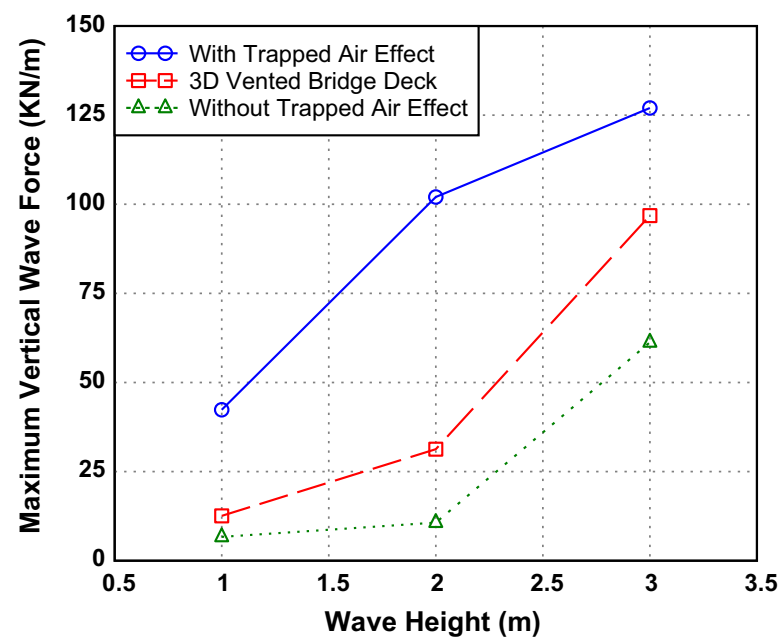

(b)

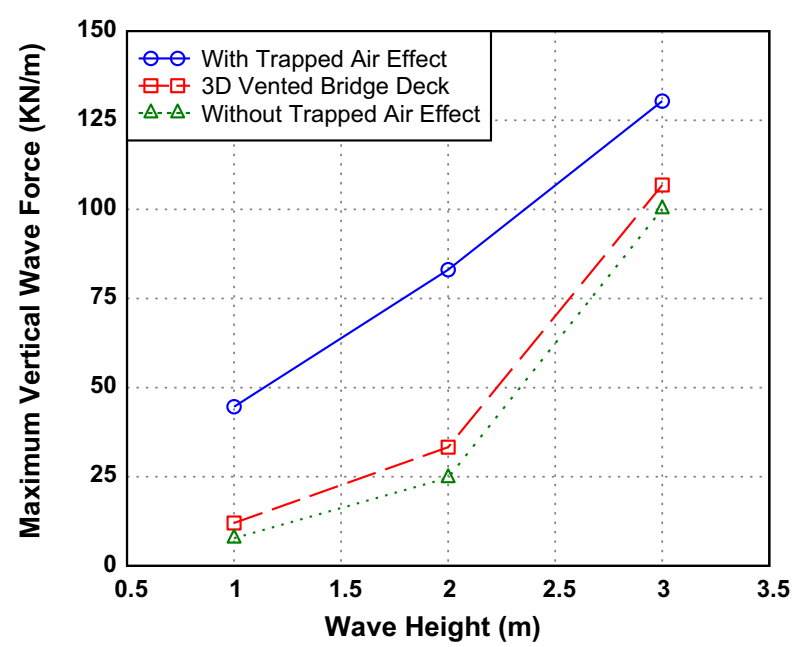

(c)

Fig. 18 Comparison of vertical wave forces on the five-girder bridge superstructure considering various wave periods. a Wave period $=4 \mathrm{~s}$. b Wave period $=6 \mathrm{~s}$. $\mathbf{c}$ Wave period $=8 \mathrm{~s}$

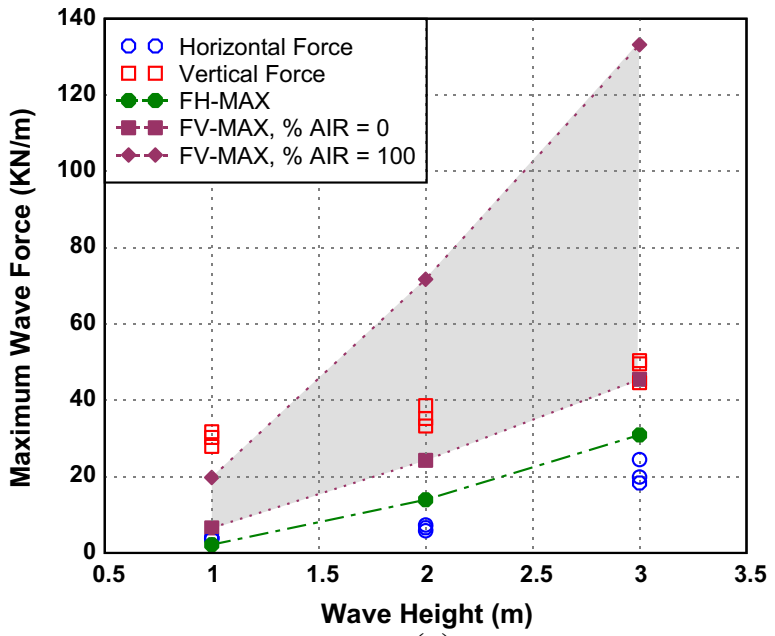

(a)

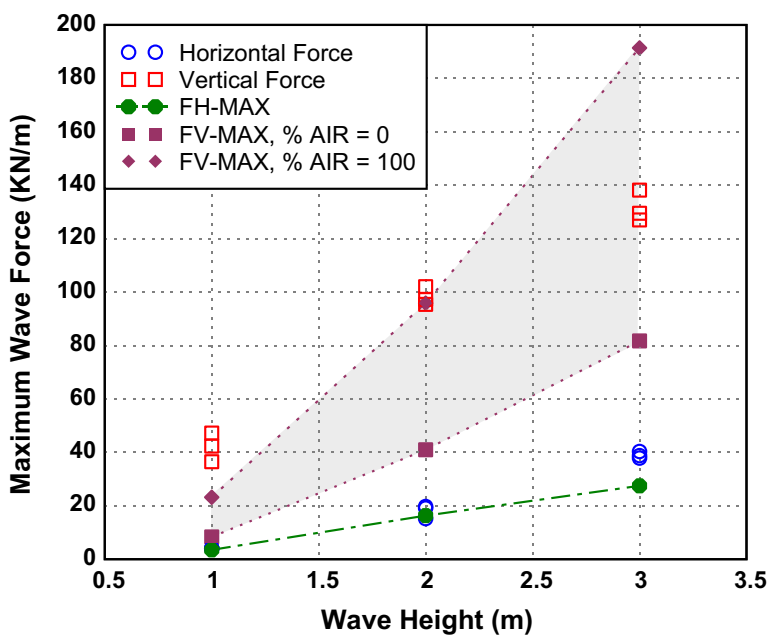

(b)

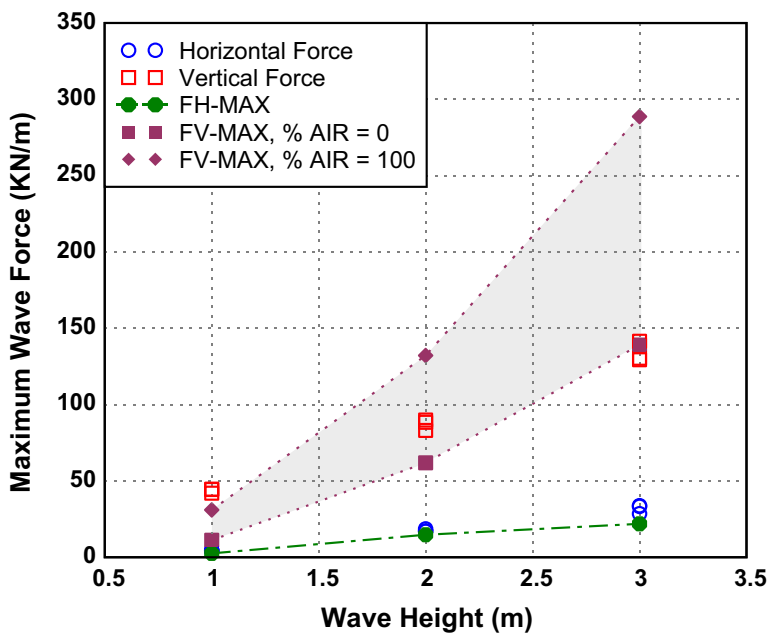

(c)

Fig. 19 Comparison of numerical calculations of wave forces against estimations of AASHTO considering various wave periods, wave heights, and bridge superstructure geometries. a Wave period $=4 \mathrm{~s}$. b Wave period $=6 \mathrm{~s}$. $\mathbf{c}$ Wave period $=8 \mathrm{~s}$ 
flow) movement of the trapped air; thus a 2D numerical model can successfully duplicate the physical behavior in a $3 \mathrm{D}$ setup.

- The water flow field is highly influenced by the amount of trapped air between the bridge girders during the wave actions as the amount of the trapped air can significantly increase the uplift force acting on the bridge superstructure.

- Single-phase simulation neglecting the trapped air effect showed almost perfect sinusoidal wave profile when the wave crest was under the bridge superstructure, while in two-phase simulations including the trapped air effect, the trapped air between the bridge girders imposed a resistance against the wave impacting the bridge superstructure, and for a particular case, preventing it from reaching the bottom of the deck and significantly modifying the wave profile under the bridge superstructure.

- Single-phase simulations neglecting the effect of the trapped air resulted in much lower vertical (uplift) wave forces compared to two-phase simulations. For the bridges studied, the vertical (uplift) wave forces were found to be 57-88 \%, on average, lower for the range of wave periods considered when the effect of the trapped air was neglected.

- The results suggest that the trapped air effect is important and is responsible for increasing the vertical wave force, especially for wave conditions in which the waves do not reach the bridge deck. In these situations, the vertical force is mainly a result of buoyancy force during the passage of the wave under the bridge superstructure.

- The trapped air effect is higher for waves with a relatively shorter period. The dynamic amplification due to the presence of the trapped air decreases with increasing wave period.

- Although the trapped air effect is found to be sensitive to the wave period and that it decreases as the wave period increases, it is most sensitive to the wave height among the factors studied in this research. The degree of sensitivity of the trapped air effect to wave height is highly influenced by the wave period. Results reveal that the trapped air effect is less sensitive to changes in the wave height for shorter wave periods, while the reduction in the trapped air effect could be significant as the wave height increases with longer period.

- Bridge deck air vents were found to be effective in reducing the uplift forces. Results showed that the vertical wave forces were decreased by $56 \%$ on average using a vent with area of $3 \%$ of the deck area, located at the downwave end of the bridge deck span.

- A comparison of the numerical calculations of the horizontal wave forces against the maximum quasi-static force estimations of AASHTO showed that the design expression of the maximum horizontal force could lead to a reasonable estimate of the wave forces on bridge superstructures. However, the design expression for maximum horizontal force could overestimate the wave force for short period waves.

- The AASHTO design expression for the maximum quasistatic vertical force may underestimate the forces for waves with small wave heights. On the other hand, for larger wave heights; use of the maximum \%AIR value could substantially overestimate the vertical force. This indicates that there is room for improvements in determining the \%AIR to provide a better estimation of the wave forces on bridge superstructures.

Acknowledgments The authors are grateful for the Glenn Willis Holcomb fund provided by the Oregon State University, School of Civil and Construction Engineering.

\section{References}

AASHTO (2008) Guide specifications for bridges vulnerable to coastal storms. American Association of State Highway and Transportation Officials, Washington, D.C

Azadbakht M, Yim S (2014) Simulation and estimation of tsunami loads on bridge superstructures. J Waterw Port Coast Ocean Eng ASCE 141(2). doi:10.1061/(ASCE)WW.1943-5460.0000262 (04014031)

Azadbakht M, Yim S (2015) Estimation of Cascadia local tsunami loads on Pacific Northwest bridge superstructures. J Bridg Eng ASCE. doi:10.1061/(ASCE)BE.1943-5592.0000755 (04015048)

Bozorgnia M, Lee J-J (2012) Computational fluid dynamic analysis of highway bridges exposed to hurricane waves. In: ICCE 2012-the 33rd international conference on coastal engineering, Santander

Bozorgnia M, Lee J-J, Raichlen F (2010) Wave structure interaction: role of entrapped air on wave impact and uplift forces. In: ICCE 2010 - the 32nd international conference on coastal engineering, Shanghai

Bradner C (2008) Large-scale laboratory observations of wave forces on a highway bridge superstructure. MS thesis, Oregon State University, Corvallis

Bradner C, Schumacher T, Cox D, Higgins C (2011) Experimental setup for a large-scale bridge superstructure model subjected to waves. J Waterw Port Coast Ocean Eng 137(1):3-11

Cuomo G, Shimosako K, Takahashi S (2009) Wave-in-deck loads on coastal bridges and the role of air. Coast Eng 56:793-809. doi:10. 1016/j.coastaleng.2009.01.005

Douglass SL, Chen Q, Olsen JM, Edge BL, Brown D (2006) Wave forces on bridge decks. Final report prepared for US Department of Transportation and Federal Highway Administration Office of Bridge Technology, Washington, D.C

Fenton JD (1985) A fifth-order stokes theory for steady waves. J Waterw Port Coast Ocean Eng 111(2):216-234

Hallquist JO (2006) LS-DYNA theory manual. Livermore Software Technology Corporation, Livermore

Hayatdavoodi M, Ertekin RC (2015a) Wave forces on a submerged horizontal plate, part I: theory and modeling. J Fluids Struct 54(April):566-579

Hayatdavoodi M, Ertekin RC (2015b) Wave forces on a submerged horizontal plate, part II: solitary and cnoidal waves. J Fluids Struct 54(April):580-596 
Hayatdavoodi M, Seiffert B, Ertekin RC (2014) Experiments and computations of solitary-wave forces on a coastal-bridge deck. Part II: deck with girders. Coast Eng 88:210-228

Hayatdavoodi M, Seiffert B, Ertekin RC (2015) Experiments and calculations of cnoidal wave loads on a flat plate in shallow water. J Ocean Eng Mar Energy 1(1):77-99

Huang W, Xiao H (2009) Numerical modeling of dynamic wave force acting on Escambia bay bridge deck during Hurricane Ivan. J Waterw Port Coast Ocean Eng 135(4):164-175. doi:10.1061/ (ASCE)0733-950X(2009)135:4(164)

Jin J, Meng B (2011) Computation of wave loads on the superstructures of coastal highway bridges. Ocean Engi 38(17-18):2185-2200

Okeil AM, Cai CS (2008) Survey of short- and medium-span bridge damage induced by Hurricane Katrina. J Bridg Eng 13(4):377387

Padgett J, DesRoches R, Nielson B, Yashinsky M, Kwon O-S, Burdette N, Tavera E (2008) Bridge damage and repair costs from Hurricane Katrina. J Bridg Eng 13(1):6-14

Robertson IN, Riggs HR, Yim SC, Young YL (2007a) Lessons from Hurricane Katrina storm surge on bridges and buildings. J Waterw Port Coast Ocean Eng 133:463-483

Robertson IN, Yim SC, Riggs HR, Young YL (2007b) Coastal bridge performance during Hurricane Katrina. Proc Struct Eng Mech Comput 3:1864-1870

Robertson I, Yim S, Tran T (2011) Case study of concrete bridge subjected to hurricane storm surge and wave action. Solut Coast Disasters 2011:728-739
Seiffert B, Ertekin RC, Robertson IN (2014a) Experimental investigation on the role of entrapped air on solitary wave forces on a coastal bridge deck. In: Proc., 33rd int. conf. on ocean, offshore and arctic eng. ASME, San Francisco, pp 1-8

Seiffert B, Hayatdavoodi M, Ertekin RC (2014b) Experiments and computations of solitary-wave forces on a coastal-bridge deck. Part I: flat plate. Coast Eng 88:194-209

Seiffert B, Hayatdavoodi M, Ertekin RC (2015) Experiments and calculations of cnoidal wave loads on a coastal-bridge deck with girders. Eur J Mech B Fluids 52:191-205

Sheppard DM, Marin J (2009a) Storm surge and wave loading on bridge superstructures. In: Structures Congress '09. American Society of Civil Engineers, Austin, Texas, pp 557-566

Sheppard DM, Marin J (2009b) Wave loading on bridge decks. Final report BD545-58, Florida Department of Transportation, Tallahassee

Souli M, Benson DJ (2010) Arbitrary Lagrangian Eulerian and fluidstructure interaction: numerical simulation. Wiley, New York

Yim SC, Olsen MJ, Cheung KF, Azadbakht M (2014a) Tsunami modeling, fluid load simulation, and validation using geospatial field data. J Struct Eng ASCE 140(8). doi:10.1061/(ASCE)ST. 1943-541X.0000940

Yim SC, Wei Y, Azadbakht M, Nimmala S, Potisuk T (2014b) Case study for tsunami design of coastal infrastructure: spencer creek bridge, Oregon. J Bridg Eng ASCE 20(1). doi:10.1061/ (ASCE)BE.1943-5592.0000631 